\title{
Claus Zittel
}

\section{Im Zwielicht. Schatten-Dialoge bei Andersen, Fechner und Nietzsche}

\author{
An das Ideal. \\ Wen liebt ich so wie dich, geliebter Schatten! \\ Ich zog dich an mich, in mich - und seitdem \\ Ward ich beinah zum Schatten, du zum Leibe. \\ Nur daß mein Auge unbelehrbar ist, \\ Gewöhnt, die Dinge außer sich zu sehen: \\ Ihm bleibst du stets das ew'ge »Außer-mir«. \\ Ach, dieses Auge bringt mich außer mich!
}

( $\mathrm{N} \mathrm{I} 882, \mathrm{I}[\mathrm{IO} 3])$

\section{Die Spur des Schattens}

Nietzsche schätzte den Dialog als philosophische Form. ${ }^{\mathrm{I}}$ Unter den vielen Dialogen, die er selbst schrieb, sticht der zwischen dem » Wanderer und seinem Schatten hervor. $^{2}$ Das gleichnamige Buch ist heute als Nachtrag zu MA I geläufig, wurde aber zuerst separat veröffentlicht und kann als ein eigenständiges Werk Nietzsches gelten. ${ }^{3}$ Seinen Titel verdankt es seinen Rahmendialo-

I Vgl. Claus Zittel, Der Dialog als philosophische Form bei Nietzsche, in: Nietzsche-Studien 45 (2016), S. 8I-I I 2; ders., "Gespräche mit Dionysos". Nietzsches Rätselspiele, in: Nietzsche-Studien 47 (2018), S. 70-99. Im erstgenannten Aufsatz habe ich die Dialoge des Wanderers mit seinem Schatten bereits kurz formal charakterisiert, nun sollen sie eingehender studiert werden.

2 Siehe dazu Luca Lupo, Ombres. Notes pour une interprétation du dialogue de Nietzsche Le Voyageur et son ombre, in: Nietzsche. Philosophie de l'esprit libre. Etudes sur la genèse de Choses humaines, trop humaines, hg. von Paolo D'Iorio und Olivier Ponton, Paris: Éditions rue d'Ulm/Presses de l'E.N.S. 2004, S. 99-I I 2.

3 Tobias Brücker, Auf dem Weg zur Philosophie. Friedrich Nietzsche schreibt »Der Wanderer und sein Schatten", Paderborn: Fink 2019; vgl. auch den 
gen, in welchen sich ein Wanderer mit seinem Schatten unterredet. Doch nicht der Wanderer, sondern sein Schatten verleiht diesen Dialogen ihre besondere Prägung: Der Schatten eröffnet das Gespräch, der Schatten lenkt es, der Schatten ist das Thema der Dialoge, deren Form er zugleich bestimmt. Es sind Schatten-Dialoge. Deren Form und Funktion will ich im folgenden beschreiben und dazu Vorläufer aus der Tradition in Erinnerung rufen, in deren >Licht die bei Nietzsche versammelten Motive und Motivketten bislang unbeachtete Deutungsfacetten offenbaren.

Seitens der Forschung wird eine solche Erkundung der Motivgeschichte erstaunlich selten unternommen. Kommentatoren aus der Philosophie zeigen, sobald bei Nietzsche von Schatten die Rede ist, in Platons Höhle 4 oder auf die Sonne der Aufklärung. ${ }^{5}$ Es genügt ihnen, je nach Kontext die platonische Lichtmetaphysik oder die aufklärerische Lichtmetaphorik heranzuziehen, um dann, im Einklang mit einer langen Tradition, die Rolle des Schattens für die Erkenntnis - entweder als Durchgangsstadium oder aber als Mittel der Konturierung - herauszuarbeiten: Das Schärfen der Erkenntnis durch sukzessive Aufklärung und Beseitigung des Schattens.

Nichts liegt mir ferner, als Nietzsches beständige Auseinandersetzung mit Platon zu bestreiten oder ihn gar als Gegenaufklärer $\mathrm{zu}$ betrachten. Gleichwohl gibt es eine weitere Traditionslinie des Schattenmotivs, die Nietzsches Schatten mit der Romantik verbindet. ${ }^{6}$ Mögliche Bezüge auf Chamissos Geschichte von

Beitrag von Tobias Brücker im vorliegenden Band. Nietzsche hat im übrigen noch einer anderen Schrift, die er bereits weitgehend fertiggestellt hatte, einen Schatten-Titel geben wollen: Friedrich Nietzsche, L'Ombra di Venezia, hg. von Jochen Strobel, Dresden: Thelem 2006.

4 Vgl. den Beitrag von Hans Ruin im vorliegenden Band.

5 Andrea Bertino, Lichtmetaphorik und Schatten Gottes in Nietzsches neuer Aufklärung, in: Archiv für Begriffsgeschichte 57 (201 5), S. 197-2 I6; Steffen Dietzsch, Wandern als Aufklärung? Nietzsches Wanderer und sein Schatten, in: Nietzscheforschung Sonderband 2: Nietzsche - Radikalaufklärer oder radikaler Gegenaufklärer?, hg. von Renate Reschke, Berlin: Akademie Verlag 2004, S. 67-80.

6 Vgl. die Bezüge, die Carlos Idrobo über die Wanderer-Figur (insb. Zarathustra als Wanderer) zur Romantik aufweist: ders., He Who Is Leaving ... The Figure of the Wanderer in Nietzsche's Also sprach Zarathustra and Caspar 
Peter Schlemihl,7 der seinen Schatten verkaufte, ${ }^{8}$ wären genauso zu prüfen wie die auf unbekanntere Texte, vor allem auf Hans Christian Andersens Märchen über den Schatten, Skyggen, ${ }^{9}$ das Chamissos Schlemibl auf originelle Weise adaptierte, ${ }^{10}$ aber auch auf heute vergessene mögliche Vorbilder wie ein kleiner Text Gustav Theodor Fechners, der einen >Dialog mit einem Schatten< (s.u.) enthält, den Nietzsche seiner Bibliothek einverleibte.

Womöglich hat man diesen Motivstrang deshalb vernachlässigt, weil Nietzsche in seiner späteren Vorrede zu MA II im Jahr I 886 WS als Frucht einer fortgesetzten »antiromantischen Selbstbehandlung « bezeichnet hatte, die er nun, nach »sechs Jahren der Genesung «, mit den anderen Schriften vereine (MA II, Vorrede, 2). Man kann daraus allerdings folgern, daß er zum Zeitpunkt des Erscheinens von WS seine »zeitweilige Erkrankung an der gefährlichsten Form der Romantik « (ebd.) noch nicht überwunden hatte. Doch je stärker er mit seinen später verfaßten Vorreden seine früheren Schriften umdeutet, desto

David Friedrich's Der Wanderer über dem Nebelmeer, in: NietzscheStudien 4I (20I2), S. 78-IO3. Idrobos schöner Aufsatz thematisiert indes nicht, inwiefern der Schatten das Wanderer-Bild >reflektiert< und bricht. Zum Wanderer-Motiv bei Nietzsche vgl. auch Claus Zittel, Abschied von der Romantik im Gedicht. Friedrich Nietzsches "Es gebt ein Wandrer durch die Nacht", in: Nietzscheforschung 3 (1994), S. 193-206.

7 Friedrich Baron de la Motte Fouqué (Hg.), Peter Schlemibl's wundersame Geschichte. Mitgeteilt von Adelbert von Chamisso, Nürnberg: Johann Leonhard Schrag I 8 I 4.

8 Ernst Loeb, Symbol und Wirklichkeit des Schattens in Chamissos "Peter Schlemibl", in: Germanisch-Romanische Monatsschrift is (1965), S. 398408.

$9 \mathrm{Vgl}$. dazu insbesondere auch den Aufsatz von Hans Ruin im vorliegenden Band. Aufgrund einer märchenhaften Koinzidenz haben wir beide auf der gleichen Silser Tagung über das gleiche Thema selbst gleichsam als Wanderer und Schatten gesprochen.

Io Andersens Märchen wurden, wie auch sein Bilderbuch obne Bilder, von Nietzsche sehr geschätzt. Vgl. dazu Claus Zittel, »Dem unheimlichen Bilde des Mährchens gleich". Überlegungen zu einer poetologischen Schlüsselstelle in Nietzsches Die Geburt der Tragödie aus dem Geiste der Musik, in: Orbis Litterarum 2014 (69/I), S. 57-78; Bastian Strinz, Robert Walser und Friedrich Nietzsche - ein poetologischer Vergleich, Berlin: de Gruyter 2019, S. $53-57$. 
reizvoller ist es, die von ihm absichtsvoll verwischten Spuren wiederaufzunehmen.

Warum aber verspricht der Blick auf die Schatten der Romantik lohnender zu sein als der auf Platon? In Platons Ideenlehre ist der Schatten bekanntlich nur Schein des Scheins, er wird gnoseologisch, axiologisch und ontologisch gegenüber den Ideen, denen allein Wahrheit zukommt, als defizitär bestimmt. Daher lag Heideggers Versuch nahe, Nietzsches Philosophie als »Umkehrung des Platonismus « zu deuten, und diese Formel ist seither zu einem häufig variierten Topos der NietzscheDeutung geworden. ${ }^{\text {II }}$ So diskutabel die Frage nach Nietzsches Umkehrung und Umwertung platonischer Rangordnungen ist, so problematisch erscheint die damit einhergehende Unterstellung, er würde damit die metaphysische Tradition unter umgekehrten Vorzeichen fortschreiben. ${ }^{\mathrm{I}}$ Wie wir auch anhand von Nietzsches Schatten-Dialogen sehen werden, wird das platonische Stufenmodell vielmehr aufgegeben, um auf planer Bühne Schattenspiele im Flackerlicht verschiedener Lichtquellen zu inszenieren. Wenn es um die Dialektik von Wesen und Schein geht, markiert die Frage nach dem Status des Schattens daher eine Wasserscheide für konträre Nietzsche-Deutungen.

In Nietzsches Schattendialogen finden sich zudem mindestens acht weitere Themenkomplexe, die bei Platon keine Rolle spielen: Die mit der Ich-Verdoppelung ( I) einhergehende Identitätsproblematik (2), der Kampf zwischen Abbild und Original (3) und mithin die Frage nach der Autorschaft (4), die Kritik der Eitelkeit (5), das Problem von Herrschaft und Knechtschaft (6), das linguistische Problem der dunklen Worte (7) und die Vorstellung vom Gespräch als Gemälde (8). Zu erwähnen sind zudem die neuen Motive des guten Europäers, des ewigen Juden, des Nar-

I I Ausgangspunkt ist ein frühes (!) Notat Nietzsches: »Meine Philosophie umgedrehter Platonismus: je weiter ab vom wahrhaft Seienden, um so reiner schöner besser ist es. Das Leben im Schein als Ziel.« (N I 870, 7[ I s6]).

I 2 Martin Heidegger, Nietzsche, Pfullingen: Neske I96I, Bd. I, S. 469. Vgl. dazu treffend Werner Stegmaier, Metaphysische Interpretation eines AntiMetaphysikers, in: Heidegger-Handbuch. Leben - Werk - Wirkung, hg. von Dieter Thomä, Stuttgart: Metzler 2003, S. 202-2 Io. 
ren und das des Hundes, das hier inter alia auf den Kyniker Diogenes verweist. ${ }^{13}$ Für eine Ausdeutung der Wanderer-SchattenKonstellation bei Nietzsche wären also noch andere Deutungshorizonte abzuschreiten, vor deren Hintergrund sukzessive weitere Aspekte der Schattenproblematik aufscheinen. Irritierend ist daher, daß in literaturgeschichtlichen Studien Nietzsches Wanderer und sein Schatten kaum je behandelt wurde, ${ }^{\mathrm{I}}$ und wenn, dann hat man mögliche Bezüge auf die literarische Tradition schroff abgewiesen - ich zitiere aus einer nach wie vor einschlägigen Monographie zum Schattenmotiv in der Literatur:

Weder geht es Nietzsche um die literarische Bearbeitung eines Motivs im Sinne der schöngeistigen Ausgestaltung und fiktionalen Aufbereitung, noch geht es ihm um den DoppelgängerSchatten als Antagonisten einer fiktiven Handlung. Sein Beitrag gehört, wenn er überhaupt literarischer Ortung bedarf, eher in die Geschichte des Schattensymbols allgemein, und da er überdies mehr schöngeistige Einkleidung, Vehikel der Gedankenvermittlung als selbstwertige Motiventfaltung ist, soll er hier nur kurz gestreift werden [...]. Mit der Reduktion des Motivs zur philosophischen Allegorie: Schatten als Gesprächspartner des Einsamen, Schattenlosigkeit als höchste

I 3 Vgl. WS, Schlußdialog: »Der Wanderer: [...] Hast du keinen Wunsch? / Der Schatten: Keinen, ausser etwa den Wunsch, welchen der philosophische >Hund vor dem grossen Alexander hatte: gehe mir ein Wenig aus der Sonne, es wird mir zu kalt."Vgl. WS i 8: »Der moderne Diogenes. - Bevor man den Menschen sucht, muss man die Laterne gefunden haben. - Wird es die Laterne des Cynikers sein müssen? - «. Zum Motiv des Hundes vgl. auch die in Anm. 28 zitierte Passage des WS-Schlußdialogs.

I4 Ausnahme ist die studentische Hausarbeit von Lena Wesemann, die bereits wichtige Hinweise auf Andersen gibt: Nietzsches, Wanderer und sein Schatten - der Schatten als Doppelgänger? (201 I); www.academia. edu/I I 827203 /Nietzsches_Wanderer_und_sein_Schatten_der_Schatten_ als_Doppelgänger (abgerufen am 29. Mai 2020) sowie der auf Chamisso hinweisende Aufsatz von Katharina Grätz, "Der Dichter verräth sich in seinen Gestalten " - und bleibt ungreifbar. Nietzsche, Zarathustra und Zarathustras Schatten, in: Nietzscheforschung 25 (2018), S. I23-I36. Grätz gibt auch einen Überblick über weitere Deutungen des Schattens in der Nietzsche-Forschung, die teils so absurd sind, daß ich sie lieber nicht anführe, um ihre weitere Verbreitung nicht zu befördern. 
Stufe der Einsamkeit, erschöpft sich jedoch Nietzsches Beitrag zum Motiv der Schattenlosigkeit. Einem Motiv, dessen selbstwertige Behandlung einerseits nicht beabsichtigt war und das andererseits mit der Gedankenwelt Nietzsches nur in so lockerem Zusammenhang steht, daß es sich wie eine äußerliche literarische Schmuckform davon isolieren und isoliert betrachten läßt. ${ }^{\text {Is }}$

Wilperts formvergessene Betrachtung reduziert die SchattenDialoge auf das Selbstgespräch eines einsamen Philosophen; ${ }^{16}$ zwangsläufig bleibt so Nietzsches auf die Romantik zurückverweisende >Philosophie des Schattens< unerkannt. Ihren Sinn sucht und findet diese gerade im Zwielicht des Un- oder nur Halbbewußten. Schattenbilder vermögen das Vage, Undeutliche, Dunkle und Rätselhafte zur Darstellung zu bringen, ohne es begrifflich einzufangen. Der Schatten figuriert zudem als Doppelgänger und Todesbote, der einen Ich-Verlust anzeigt oder - mit der gleichen Folge - eine Vervielfältigung des Ichs herbeiführt: lauter fiktive Ichs entstehen - und kein wahres Ich bleibt bestehen. Dieser Weg ins Dunkle, in dem das Ich sich auflöst und die Zeichen ihre klaren Referenten verlieren, führt ins schwarze Herz von Nietzsches Philosophieren.

In der Romantik ${ }^{17}$ bekommt der Schatten sein eigenes Recht: Er kann den Menschen substituieren, an seine Stelle treten, sei-

Is Gero von Wilpert, Der verlorene Schatten. Varianten eines literarischen Motivs. Stuttgart: Kröner 1978, S. I27. Zur Kritik an Wilpert siehe bereits Wesemann, Nietzsches Wanderer, S. 3, und Grätz, Der Dichter verräth sich in seinen Gestalten, S. I 34 .

I6 So hat es auch schon Giorgio Colli in seinem Nachwort zu MA in KSA 2, S. 7I 2 f. gesehen.

I7 Vgl. zur Tradition und Vieldeutigkeit des Schattenmotivs: Peter Jackob, Der Schatten. Wandel einer Metapher in der europäischen Literatur, Sulzbach: Kirsch 200I; Homer Berndl, Semantik der Verdunkelung. Die Ambivalenzen des "Schatten"-Motivs und ibre Tradition in der Literatur der früben Moderne, Würzburg: Königshausen und Neumann 2016; dazu Katharina Grätz, Der Dichter verräth sich in seinen Gestalten, S. I 33. Zum Doppelgänger vgl. Hans Richard Brittnacher, Markus May, Revenant/Doppelgänger, in: Phantastik. Ein interdisziplinäres Handbuch, hg. von dens., Stuttgart: Metzler/Springer 2013, S.466-472; Ingrid Fichtner (Hg.), Doppelgänger Von endlosen Spielarten eines Phänomens, Bern: Haupt 1999; Monika 


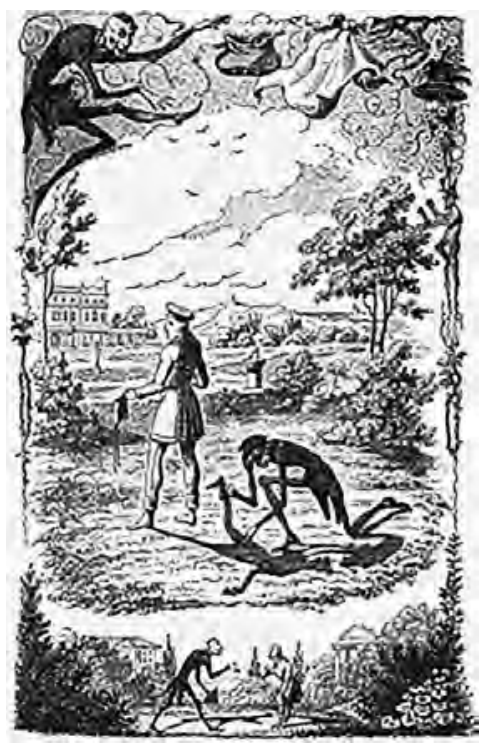

Abb. 24: George Cruikshank, Illustration zur ersten englischen Ausgabe des Peter Schlemihl, London: Whittaker 1824, übersetzt von John Bowring

nen Standpunkt mit dem gleichen Recht vertreten, kurzum, das Verhältnis von Original und Schattenbild wird in die Horizontale gekippt, und beide Perspektiven sind von nun an strukturell gleichberechtigt, ohne in ihrem Perspektivismus jedoch eine neue stabile horizontale Ordnung zu begründen; es ergibt sich eher ein Mobile der Perspektiven. In Chamissos Erzählung kann der Schatten verkauft oder geraubt werden, ist aber immer an eine Person gebunden. ${ }^{18}$ Eine Person kann auch mehrere Schat-

Schmitz-Emans, Zwillinge/Doppelgänger, in: Metzler Lexikon literarischer Symbole, hg. von Günter Butzer und Joachim Jacob, Stuttgart: Metzler 2008, S. 502-504; Christof Forderer, Ich-Eklipsen. Doppelgänger in der Literatur seit I 800, Stuttgart: Metzler 1999; Birgit Fröhler, Seelenspiegel und SchattenIch. Doppelgängermotiv und Anthropologie in der Literatur der Romantik, Marburg: Tectum 2004; Gerald Bär, Das Motiv des Doppelgängers als Spaltungsphantasie in der Literatur und im deutschen Stummfilm (Internationale Forschungen zur Allgemeinen und Vergleichenden Literaturwissenschaft, Bd. 84), Amsterdam: Rodopi 2005; Guido Davico Bonino (Hg.), Essere due. Sei romanzi sul doppio, Turin: Einaudi 2006.

I 8 »Er [der graue Mann] schlug ein, kniete dann ungesäumt vor mir nieder, und mit einer bewundernswürdigen Geschicklichkeit sah ich ihn meinen 
ten haben, aber die Schatten bleiben stets Knechte ihrer Herren, was auch bereits die frühen Illustrationen verdeutlichten.

Erst wenn der Schatten sich mit dem Doppelgängermotiv verschränkt, verselbständigt er sich - und erst das schafft die Voraussetzung für das ganz und gar anti-platonische Szenario, das auch bei Nietzsche gegeben ist, in dem ein lebendiger Schatten dazu befähigt ist, in einen Dialog einzutreten. Diese Lebendigkeit des Schattens, das ist meine Leitthese, verleiht auch Nietzsches Schatten seine Besonderheit, über sie gilt es also nachzudenken und ihren Ursprüngen nachzuspüren.

\section{Der Verrat der Poesie: Hans Christian Andersens Der Schatten}

Die erste Fährte führt zu Andersens Anti-Märchen Der Schatten. ${ }^{19}$ Es ist eine Geschichte über »Poesie und Verrat ${ }^{20}$ Ein junger Gelehrter aus dem Norden zieht in den heißen Süden, wo er der Hitze wegen meist zuhause bleibt. In dem stillen und vermeintlich leeren Haus gegenüber erklingt manchmal aus einem Balkonzimmer leise Musik, und einmal, als der Gelehrte nachts aufwacht, erblickt er inmitten der Balkonblumen eine junge Frau, die zu leuchten scheint. Als er genauer hinschaut, ist alles verschwunden, nur die Musik ist noch zu hören. An einem anderen Abend beobachtet er, wie sein eigener Schatten mit der untergehenden Sonne die gegenüberliegende Hauswand hinaufwandert. »Ich glaube, mein Schatten ist wohl das einzig Lebendige, was man da drüben erblickt ${ }^{2}{ }^{21}$ sagt er zu sich. Als er aufsteht, erhebt sich mit ihm auch sein Schatten auf dem Nach-

Schatten, vom Kopf bis zu meinen Füßen, leise von dem Grase lösen, aufheben, zusammenrollen und falten, und zuletzt einstecken« (Chamisso, Peter Schlemibl, S. I4).

I9 In: Hans Christian Andersen, Sämtliche Märchen, übersetzt von Julius Reuscher, Leipzig: Ernst Julius Günther I 876, S. 457-472. Die erste deutsche Ausgabe erschien in: Andersen, Gesammelte Märchen, Leipzig: Carl B. Lorck I 847 , Bd. 4, S. 90-I Io.

20 So Michael Maar in seinem Nachwort zu Hans Christian Andersen: Schräge Märchen, übersetzt und hg. von Heinrich Detering, München: Eichborn $200 \mathrm{I}$.

2 I Andersen, Sämtliche Märchen, S. 459. 
barbalkon, und als er sich umdreht und ins Zimmer geht, tut es ihm der Schatten auf der anderen Seite gleich. Am folgenden Tag bemerkt der Gelehrte beim Ausgehen, daß er keinen Schatten mehr hat. Er ärgert sich, »doch nicht so sehr, daß der Schatten fort war, sondern weil er wußte, daß es eine Geschichte giebt von einem Manne ohne Schatten, diese kannten ja alle Leute daheim in den kalten Ländern, und käme nun der gelehrte Mann dorthin und erzählte die seine, so würde man sagen, daß er nur nachzuahmen suche «. ${ }^{22}$ Sein Leben erscheint ihm als Plagiat der Literatur. Der Schatten bleibt verschwunden, aber nach einiger Zeit wächst dem Gelehrten (im Unterschied zu Schlemihl) ein neuer, deutlich kleinerer, aber doch akzeptabler Schatten nach. Nachdem er in den Norden zurückgekehrt war, steht nach vielen Jahren ein fein angezogener magerer Mensch vor seiner Tür, der ihn fragt, ob er ihn nicht wiedererkenne. Der Schatten hat inzwischen Fleisch angesetzt, ist vermögend geworden und sehnt sich nun danach, seinen früheren Besitzer wiederzusehen, bevor dieser sterbe, um sich freizukaufen. Unter der Bedingung, daß der Gelehrte das Geheimnis seiner wahren Identität nicht verrate, erklärt sich der Schatten bereit, seine Geschichte zu erzählen. Der Gelehrte ist einverstanden: » ein Mann, ein Wort! `Ein Wort, ein Schatten!««, schlägt der Schatten ein und stellt sich auf den neuen Schatten des Gelehrten, der diesem »wie ein Pudel zu Füßen lag«. ${ }^{23}$ Im Nachbarhaus habe, erzählt er nun, die Poesie gewohnt, bei dieser habe er alles gesehen, was man sehen kann, und seither wisse er auch alles - er sei dabei zum Menschen geworden; zugleich habe er seine innerste Natur entdeckt, nämlich seine Verwandtschaft mit der Poesie. ${ }^{24}$ Danach sei er ausgegangen und habe überall heimlich durch die Fenster geschaut und dabei gesehen, was keiner sehen wollte und wissen durfte: die ganze Niedertracht der Welt: »[H]ätte ich eine Zeitung geschrieben, die wäre gelesen worden! Aber ich schrieb gerade an die Personen selbst, und es entstand ein Schrecken in allen Städten, in die ich kam. [...] Die Lehrer machten mich

22 Ebd., S. 460.

23 Ebd., S. 46If.

24 Ebd., S. 465 . 
zum Lehrer, die Schneider gaben mir neue Kleider [...] und die Frauen sagten, ich sei schön! $\ll^{25}$

Seither wohnt der Schatten auf der Sonnenseite des Lebens, der Gelehrte jedoch muß sich deprimiert eingestehen, daß niemand seine Schriften über das Wahre, Gute und Schöne mehr lesen will. Als der Schatten ihm anbietet, sein Reisebegleiter zu werden - und zwar als sein Schatten! -, lehnt er die unverschämte Offerte zunächst ab. In den folgenden Jahren wird der Gelehrte immer kränker und muß sich anhören, er sehe aus wie ein Schatten. Als ihn der Schatten bei seinem nächsten Besuch $\mathrm{zu}$ einer Reise ins Kurbad einlädt, willigt er schließlich ein. Der Gelehrte bietet dem Schatten das Du an, was dieser pikiert ablehnt, ihn aber von nun an duzt.

Im Kurbad angelangt, begegnen sie einer Königstochter, die an einer besonderen Scharfsichtigkeit >leidet< und daher sieht, daß ihr neuer Kurschatten keinen Schatten wirft. Der Schatten erklärt ihr, daß er einen besonders exklusiven Schatten habe, den er zu einem Menschen habe aufputzen lassen. Beim abendlichen Tanz glänzt der Schatten mit seiner Leichtfüßigkeit und seinem Wissen. Die Königstochter überprüft dennoch mit schwierigsten Fragen seine Bildung, doch dieser behauptet dreist, die Antworten seit seiner Kindheit zu kennen, sogar sein Schatten, der ihm ja lange genug zugehört habe, könne sie geben. Also befragt die Königstochter den vermeintlichen Schatten und beeindruckt von den Antworten des Gelehrten beschließt sie den tatsächlichen Schatten zu heiraten. Dieser bietet dem Gelehrten großmütig an, mit ihm ins Schloß zu ziehen und sich dann - wie es sich für einen Schatten gehöre - zu seinen Füßen zu legen. Der Gelehrte protestiert und will die Geschichte auffliegen lassen, woraufhin ihn der Schatten gegenüber der Königstochter für verrückt erklärt, behauptend, dieser glaube, er sei der Mensch und er selbst dessen Schatten. Die Königstochter meint betroffen, daß man den armen Schatten am besten in aller Stille von seinem Leben erlösen solle. Als sie am Abend Hochzeit feiern, kommentiert der Erzähler lapidar: »Der gelehrte Mann 
hörte nichts von diesen Herrlichkeiten, - denn ihm hatten sie das Leben genommen. $\ll^{26}$

Andersens bemerkenswertes Anti-Märchen versammelt mehrere Motive, die in WS in ähnlicher oder leicht variierter Form wiederkehren, unter anderem: Der Gelehrte führt in seiner dunklen Studierstube eine Schattenexistenz, eine »vita umbratica «; ${ }^{27}$ er repräsentiert die lebensferne Wissenschaft, darüber hinaus den Verstand und das Streben nach Selbstkontrolle. Poesie und Schatten sind als Instanzen des Scheins wahlverwandt - gemeinsam verraten und besiegen sie die Wissenschaft; die Fiktion triumphiert über die Wirklichkeit. Der Schatten wird durch die Begegnung mit der Poesie lebendig, er beginnt zu sprechen, befreit sich von seinem Sklavendasein (womöglich als ein Teil-Ich, das eigene Wege geht) und unterwirft seinen früheren Besitzer, mehr noch: Er nimmt dessen Identität an. Nun ist er ganz sinnliches Ich, als versklavter Schatten hingegen existierte er wie ein Hund. ${ }^{28}$ Andersens Schatten stellt sich über die Moral, er ist Immoralist und Nihilist.

26 Ebd., S. 472.

27 Nietzsche notierte sich I 876 eine Losung, die auf Plinius zurückzuweisen scheint: »Der höhere Ehrgeiz in der vita umbratica: gründlich sich unterscheiden!« (N I 876, I6 [39]) Die vita umbratica meint die Gelehrtenexistenz in der dunklen Studierstube, wo das Schatten-Leben aus Schreiben besteht. In Schulpforta pflegte man, wie ein zeitgenössischer Bericht mitteilt, ein »die vita umbratica in Pforte feierndes Gaudeamus « zu dichten: »Auch die Toten sollen leben!« Blätter für literarische Unterhaltung, Leipzig: Brockhaus I 834 , S. I 434 .

28 Vgl. WS, Schlußdialog: »Der Schatten: Ich habe dich oft mit Schmerz verlassen: es ist mir, der ich wissbegierig bin, an dem Menschen Vieles dunkel geblieben, weil ich nicht immer um ihn sein kann. Um den Preis der vollen Menschen-Erkenntniss möchte ich auch wohl dein Sclave sein. Der Wanderer: Weisst du denn, weiss ich denn, ob du damit nicht unversehens aus dem Sclaven zum Herrn würdest? Oder zwar Sclave bliebest, aber als Verächter deines Herrn ein Leben der Erniedrigung, des Ekels führtest? Seien wir Beide mit der Freiheit zufrieden, so wie sie dir geblieben ist - dir und mir! Denn der Anblick eines Unfreien würde mir meine grössten Freuden vergällen; das Beste wäre mir zuwider, wenn es Jemand mit mir theilen müsste, - ich will keine Sclaven um mich wissen. Desshalb mag ich auch den Hund nicht, den faulen schweifwedelnden Schmarotzer, der erst als Knecht der Menschen shündisch geworden ist und von dem sie gar noch zu rühmen pflegen, dass er dem Herrn treu sei und ihm folge wie sein $-«$. 
Auch auf formaler Ebene lassen sich Korrespondenzen ausmachen: Wie bei Andersen gibt es auch in WS explizite intertextuelle Verweise auf literarische Vorgänger sowie das Wissen, daß das Bild, das sich die Nachfolger machen, übermächtig werden und den Autor auslöschen wird. "Zarathustras Schatten hat lange Beine - mit diesem Zitat hatte einst Müller-Lauter einen Aufsatz über die Wirkungsgeschichte Nietzsches betitelt. ${ }^{29}$

Aber auch Andersens Erzählung steht im Schatten Chamissos und versucht sich von ihrem Vorbild $\mathrm{zu}$ emanzipieren: Sein Schatten ersetzt das Urbild durch eine ganz neue Fiktion. Bei Chamisso bleibt der Schatten nach seinem Verkauf immer an einen Herrn gekettet. Weder agiert er eigenmächtig, noch spricht er; es gibt keinen Dialog zwischen Schlemihl und seinem Schatten. Nicht mit Chamissos Schlemihl also, sondern erst mit Andersen gewinnt das romantische Schattenmotiv jene Abgründigkeit, die auch Nietzsche anvisiert: Der Schatten gewinnt den Kampf gegen sein Urbild, er verwirrt und zerstört dessen Identität. Diese Möglichkeit wird in Nietzsches Wanderer-undsein-Schatten-Dialogen thematisiert, das Verwirrspiel dann aber erst im Zarathustra durchgeführt. Aus der Antike überliefert ist der Glaube, daß sich Schatten verselbständigen, doch vermögen sie dies erst nach dem Tod des Menschen. Noch Wieland läßt in seiner Geschichte der Abderiten anläßlich des Streites um des Esels Schatten den Gerichtsassessor Miltias schlußfolgern, daß, weil der Schatten nie ohne Esel erscheine, »ein Eselsschatten im Grunde nichts andres als ein Schattenesel« sei. ${ }^{30}$ Der verlorene

29 Wolfgang Müller-Lauter, Zarathustras Schatten hat lange Beine ..., in: Evangelische Theologie 23 (1963), S. II3-I31; Wiederabdruck in: Philosophische Theologie im Schatten des Nibilismus, hg. von Jörg Salaquarda, Berlin: de Gruyter 1971, S. 89-I I 2 und in: Der Nibilismus als Phänomen der Geistesgeschichte in der wissenschaftlichen Diskussion unseres Jabrbunderts, hg. von Dieter Arendt, Darmstadt: Wissenschaftliche Buchgesellschaft I 974, S. I69-194.

30 »Auf der einen Seite scheine nichts klarer «, sagt Miltias, »als daß derjenige, der den Esel, als das Prinzipale, gemietet, auch das Akzessorium, des Esels Schatten, stillschweigend mit einbedungen habe; oder, (falls man auch keinen solchen stillschweigenden Vertrag zugeben wollte) daß der Schatten seinem Körper von selbst folge, und also demjenigen, der die Nutznießung des Esels an sich gebracht, auch der beliebige Gebrauch seines Schattens 
Schatten ist auch bei Chamisso kein Doppelgänger - mit dem romantischen Doppelgängermotiv, das dann auch bei Jean Paul (Der Titan) und E.T.A. Hoffmann (Die Abentewer einer Sylvesternacht, Die Elixiere des Teufels, Die Doppeltgänger) die Ich-Spaltung und Selbstentfremdung der Protagonisten anzeigt, hat er nichts zu tun. Erst wenn sich Schatten- und Doppelgängermotiv verschränken und der Schatten Selbständigkeit erlangt, ist der entscheidende Wendepunkt in der Literaturgeschichte des Schattens erreicht, und erst aus der neuen Doppelgängerrolle des Schattens ergeben sich jene radikalen philosophischen Konsequenzen, die Nietzsche forciert. Dies spricht dafür, sich diese entscheidende Phase des Übergangs näher anzusehen.

\section{Gustav Theodor Fechner, Der Schatten ist lebendig!}

Ein Jahr bevor Andersens Skyggen das Licht der Welt erblickte, nämlich im Jahr i 846, veröffentlichte Gustav Theodor Fechner einen kleinen Text unter dem Titel: Der Schatten ist lebendig! Der einst als »Vollender der romantischen Naturphilosophie « ${ }^{1}$ gerühmte Gustav Theodor Fechner (I80I-I887) war einer der unzeitgemäßesten Gelehrten des i 9. Jahrhunderts. ${ }^{32}$ Als Phy-

ohne weitere Beschwerde zustehe; um so mehr, als dem Esel selbst dadurch an seinem Sein und Wesen nicht das mindeste benommen werde. Hingegen scheine auf der andern Seite nicht weniger einleuchtend, daß, wiewohl der Schatten weder als ein wesentlicher noch außerwesentlicher Teil des Esels anzusehen sei, folglich von dem Abmieter des letztern keineswegs vermutet werden könne, daß er jenen zugleich mit diesem stillschweigend habe mieten wollen; gleichwohl, da besagter Schatten schlechterdings nicht für sich selbst ohne besagten Esel bestehen könne, und ein Eselsschatten im Grunde nichts andres als ein Schattenesel sei, der Eigentümer des leibhaften Esels mit gutem Fug auch als Eigentümer des von jenem ausgehenden Schattenesels betrachtet, folglich keineswegs angehalten werden könne, letztern unentgeltlich an den Abmieter des erstern zu überlassen.« (Wieland, Geschichte der Abderiten, in: Sämtliche Werke, Leipzig: Göschen I855, Bd. I4, S. 2of.)

3I So hat ihn Wilhelm Wundt genannt. Vgl. dazu Olaf Briese, »Vollender romantischer Naturphilosophie". Weltenbaum, Weltseele und Weltgrammatik bei Gustav Theodor Fechner, in: Athenäum. Jahrbuch für Romantik s (1995), S. I97-2 I I.

32 Gert Mattenklott, Gustav Theodor Fechner. Ein deutsches Gelehrtenleben, in: Fechner und die Folgen außerhalb der Naturwissenschaften. Interdis- 
siker, Naturphilosoph, Psychologe, mystischer Theologe, Poet und Satiriker paßte er in keine der für die Wissenschaftslandschaft des i9. Jahrhunderts gebräuchlichen Rubriken. Fechner begründete vielmehr mit der Psychophysik und experimentellen Ästhetik neue methodische Ansätze, die sonst getrennte Gebiete verbanden. ${ }^{33}$ Absurde Themen verfolgte er mit wissenschaftlicher Gründlichkeit, wissenschaftliche Fragen mit ästhetischer Leichtigkeit. So entstand eine eigentümliche Spielart satirischer Schriften. Gleich sein Erstling aus dem Jahr I 82 I trug den charakteristischen Titel: Beweis, dass der Mond aus Jodine bestehe. ${ }^{34}$ I 825 läßt Fechner eine Vergleichende Anatomie der Engel 35 folgen, zeitgleich publiziert er Rätselbücher und etliche Schriften zur organischen Chemie und zum Galvanismus als Früchte einer regen Experimentiertätigkeit. Mit Vorliebe wendet er diese Methoden dann aber ironisch gegen sie selbst, etwa wenn er mit ihnen demonstriert, daß der Hexenflug existiert. ${ }^{36}$ Selbst seine metaphysischen Systementwürfe zur Pflanzenseele bleiben stets ostentativ hypothetisch ${ }^{37}$ und diskutieren jeweils den Gegenstandpunkt, manchmal bis hin zur methodischen Selbstparodie..$^{8}$ Es verwundert daher nicht, daß Fechner es war,

ziplinäres Kolloquium zum 200. Geburtstag Gustav Theodor Fechners, hg. von Ulla Fix et al., Tübingen: Niemeyer 2003, S. 7-23; hier S. 7. Vgl. auch ders., Nachwort, in: G. T. Fechner. Das unendliche Leben, München: Matthes und Seitz I984, S. I69-190; Kurd Lasswitz, Gustav Theodor Fechner, Stuttgart: Frommann I 896.

33 Vgl. weiterführend Michael Heidelberger, Die innere Seite der Natur. Gustav Theodor Fechners wissenschaftlich-philosophische Weltauffassung, Frankfurt a.M.: Klostermann I993; Manfred Thiel, Fechner, Emerson, Feuerbach, Heidelberg: Elpis 1982.

34 Gustav Theodor Fechner, Beweis daß der Mond aus Jodine bestehe, Leipzig: Germanien I 82 I.

35 Dr. Mises [Gustav Theodor Fechner], Vergleichende Anatomie der Engel. Eine Skizze, Leipzig: Baumgärtner I 825 .

36 Dr. Mises, Es gibt Hexerei, in: Kleine Schriften, Leipzig: Breitkopf \& Härtel I 875 .

37 Fechner, Zend-Avesta, III. Teil, Leipzig, Hamburg: Leopold Voß i 854 , Vorwort, S. IV.

$38 \mathrm{Vgl}$. dazu insbesondere das Vorwort zu Zend-Avesta, I. Teil, 2. Auflage, Leipzig, Hamburg: Leopold Voß: I90I, hg. von Kurd Lasswitz, S.XI: „Ich selbst bin weit entfernt, die Betrachtungen und Schlüsse dieser Schrift als absolut sicher anzusehen. [...] Ja wohl manchmal habe ich mich im 
der den Begriff »Lustprinzip « erfand. 39 I 875 versammelt er unter dem Pseudonym Dr. Mises eine Auswahl seiner wissenschaftlich-satirischen Schriften. Es sind Proben einer fröhlichen Wissenschaft, die auf Nietzsche vorausweisen, darunter ein älterer Aufsatz aus dem Jahr i 835: Heinrich Heine als Lyriker ${ }^{40}$ sowie der hier zu untersuchende Dialog mit einem Schatten. ${ }^{4}$ Wie die Forschung notierte, konnte Nietzsche mit Fechners Ideen durch dessen Präsenz in seinem Leipziger Umfeld während seiner Studienjahre sowie über Friedrich Albert Langes Materialismusbuch ${ }^{42}$ bekannt geworden sein. Nicht bemerkt wurde bisher jedoch, daß jener Band mit den kleinen Schriften Fechners sich in Nietzsches Bibliothek findet und Lesespuren aufweist. ${ }^{43} \mathrm{Da}$ diese Schrift in der Nietzsche-Forschung unbekannt ist, muß ich für den Vergleich mit WS ausführlicher aus ihr zitieren.

Rückblick auf dieselbe und betroffen von ihrem Widerspruch gegen das, was ringsum gilt, selbst gefragt: ist nicht das Ganze doch nur ein geistiges Spiel ? [...] Hast du nicht früher, dich selbst parodirend, bewiesen, dass auch der Schatten lebendig ist; ist nicht umgekehrt die Lebendigkeit, die du jetzt beweisest, ein Schattenspiel?"

39 Gustav Theodor Fechner, Über das Lustprinzip des Handelns, in: Fichtes Zeitschrift für Philosophie und phil. Kritik - Neue Folge (19) I 848, S. I-30 u.S. I63-194. Siehe dazu Imre Hermann, Gustav Theodor Fechner, in: Imago 2 (1925), S.371-420; Bernd Nitzschke, Affektregulation und Begrenzung der Wünsche: "Kulturarbeit etwa wie die Trockenlegung der Zuydersee". Anmerkungen zu Freud und Fechner, in: Psychische Regulierung, kollektive Praxis und der Raum der Gründe, hg. von Brigitte Boothe, Andreas Cremonini, Georg Kohler, Würzburg: Königshausen und Neumann 2012, S. $245-265$.

40 H. Heine als Lyriker (aus den Blättern für literarische Unterhaltung I 835), in: Dr. Mises, Kleine Schriften, S. 366-382. Vgl. dazu Claus Zittel, Gustav Theodor Fechners Heine als Lyriker und Nietzsches Heinebild: »ein elektrisches Band ", in: Heine - Nietzsche. Corrispondenze estetiche. Ästhetische Korrespondenzen, Sonderband der Studi germanici, hg. von Maria Carolina Foi, Gabriella Pelloni, Marco Rispoli und Claus Zittel, Rom: IISG 2020, S. I 57 - I 86.

4I Vier Paradoxa: I. Der Schatten ist lebendig, in: Dr. Mises, Kleine Schriften.

42 Friedrich Albert Lange, Geschichte des Materialismus und Kritik seiner Bedeutung in der Gegenwart, 2. verbesserte und vermehrte Auflage, Bd. 2: Geschichte des Materialismus seit Kant, Iserlohn: Baedeker i 875. Vgl. George J. Stack, Lange und Nietzsche, Berlin: de Gruyter, S. 224. Christian Emden, Nietzsche and the Politics of History, Cambridge: CUP 2008, S. 60 f.

43 Dr. Mises, Kleine Schriften; darin als erstes von »vier Paradoxa«: Der Schatten ist lebendig. 
Gleich zu Beginn seines Aufsatzes stellt Fechner klar, weshalb das Schattenthema nun auf bisher unerhörte Weise behandelt werden soll:

Den Schatten für lebendig zu halten, ist eigentlich nichts Neues. Schon die Alten thaten es, indem sie die Seelen nach dem Tode für Schatten erklärten, und ihnen doch eine Art Leben dabei beimaßen. Wie der Mensch seinen Schatten neben sich wirft, der mit ihm wandelt, so soll er nach den Griechen auch einen Schatten werfen, der nach ihm wandelt; wie jenen das Sonnenlicht, so diesen unser eigenes Lebenslicht erzeugen. Doch warum erst den Menschen tödten, um den Schatten lebendig zu machen? Muß es nicht den Menschen freuen, wenn der treueste Begleiter unter der Sonne, den er hat, nicht als ein Leichnam mit ihm wandelt, sondern als ein selbst Mitlebender? Und ist es nicht deshalb, daß die Sage ein Grausen knüpft an Menschen, die ihren Schatten verkauft haben. Sie haben ihren Zwillingsbruder verkauft. Hat der Teufel die Schattenseele, wird er die Lichtseele bald nachholen. [...]

Und bei all diesem Wechsel behält doch jeder Schatten seine besondere Charaktereigenthümlichkeit. Ein geistreicher Mann und ein Dummkopf können sich nicht verschiedener benehmen als ihre Schatten. Benutzt man ja doch sogar die Schattenrisse, den Charakter der Menschen festzuhalten.

Man sieht, in all diesem unterscheidet sich der Schatten nicht nur nicht von uns lebenden Wesen; er steht uns eher an selbständiger Lebendigkeit voran. ${ }^{44}$

Nun sei der Mensch aber eitel auf seine Sonderstellung im Kosmos bedacht und würde dem Schatten die Selbständigkeit nicht zugestehen wollen. Um diesen Streitpunkt auszufechten, imaginiert Fechner einen Dialog zwischen Mensch und Schatten:

Inzwischen, der Mensch bildet sich nun einmal ein, Gott habe von der ganzen Welt blos ein paar Stückchen lebendig ge- 
macht, und ist so stolz darauf, selbst zu diesen Stückchen zu gehören, daß er nun alles daran setzt, dies Privilegium auch zu behaupten. Er wird also die Ansprüche auf das Leben, die für den Schatten mit Vorigem erhoben sind, nicht gelten lassen, sondern dagegen einwenden: Alles das genügt nicht. Um leben zu können, muß man doch vor allem sein. Ein Schatten hat aber überhaupt nichts Wesenhaftes; ist ein Schein; ist nicht nur nichts, ist weniger als nichts.

Was kann der Schatten dagegen sagen? Nun zuvörderst dieselben oder gleich geltende Vorwürfe dem Menschen zurückgeben. Glaubt der Mensch nicht an das Leben seines Schatten, so kann es ihm der Schatten dadurch vergelten, daß er nicht an das Leben seines Menschen glaubt, und zwar nach gleichen und gleich guten Gründen. ${ }^{45}$

Fechner räumt ein, daß der Mensch, weil er selbst kein Schatten sei, nicht genau wissen könne, wie der Schatten sein Verhältnis zu ihm sehe, doch seien zwei Vorstellungsweisen denkbar. Erstens könne der Schatten behaupten, daß er sich zum Menschen wie der Geist zum Körper verhalte, mit dem einzigen Unterschied,

daß der Schatten als Geist neben seinem Körper hergeht, während unser Geist in seinem Körper einher geht; an sich ist aber ein räumliches Verhältnis des Geistes zum Körper so gut möglich, als das andere. Warum soll der Geist seinen Rock nicht eben so gut neben sich hängen, als anziehen können? Sieht man, wie selbst die gewiegtesten Philosophen Körper und Geist einander scharf gegenüberstellen, so könnte man sogar auf den Gedanken kommen, daß die Schattenansicht die allein wahre wäre; wenn nur die Philosophen hier für parteilos gelten könnten. Aber offenbar sind sie selbst aus dem Schattenreiche inspiriert; denn warum vertrügen ibre Sätze sonst so wenig scharfe Beleuchtung. Ich, der ich den Schatten gern ihr Recht lasse, aber unseres auch nicht verkürzt haben 
will, finde es ganz natürlich, daß die Natur in ihrem Streben, alle Möglichkeiten zu verwirklichen, beide Verhältnisse zugleich verwirklicht hat, so daß also ein Geist des Körpers in ihm, der andere neben ihm geht, und, damit sie sich nicht um denselben streiten, es so eingerichtet hat, daß jeder denkt, er habe den Leib allein. ${ }^{6}$

Hier wird die in WS so auffällige selbstreflexive Wortspielerei mit der Kürze von Schatten und Rede vorweggenommen. Über den Leib aber würde der Schatten die Hoffnung äußern, ihn eines Tages loswerden zu können:

Ohne diesen Leib könnte ich hienieden nicht bestehen; also ist er für mich da. Freilich nicht blos, um mich in diesem Jammerthale zu erhalten, sondern auch mich daran zu fesseln. Aber nicht immer hoffe ich diese schwere Masse, die sich an meine Fersen hängt, mit mir herumtragen zu müssen; nicht immer in einer Welt wandeln zu müssen, wo es mehr des Uebels, d.h. des Lichts giebt, als des Guten. ${ }^{47}$

Der Schatten irre sich womöglich, doch für Menschen wie Schatten bleibe "immer wahr, daß noch etwas hinter dem Leibe steckt, was sich nicht davor sehen läßt; obwohl der Schatten in dieser Beziehung wieder besser als wir gestellt ist, die von derselben Mauer ganz und gar umschlossen sind, welche dem Schatten bloß von einer Seite gegenübersteht. «48 Aber es sei ja noch eine weitere Vorstellung möglich - Fechner kehrt nun die Perspektiven um:

Wir sehen in unserm schwarzen Nebenmanne einerseits unseren beständigen von uns abhängigen Begleiter, anderseits ein Widerspiel unsers positiven Wesens; in demselben Verhältnisse stehen wir nun aber auch gegenseits zu unserm Schatten.

46 Ebd., S. 246. Hvg. C.Z.

47 Ebd., S. 247.

48 Ebd. 
Also kann mein Schatten mich eben so für seinen Schatten, als ich ihn für meinen Schatten halten. ${ }^{49}$

Für den Menschen sei dies aber schwer einzusehen, denn er glaube felsenfest, daß der Schatten ohne ihn nicht existieren könne:

Während ich mich bald rechts, bald links wende, wie mir's nach Tages- und Jahreszeit gefällt, bleibt er [der Schatten, C.Z.] immer ein steifer aufrechter Stock und muß immer genau die Stellung einnehmen, die meine und die Sonnenstellung ihm vorschreibt; wo ist da eine Spur von Freiheit und Selbständigkeit. Verschwinde ich, verschwindet er auch, denn nie hat ein Schatten seinen Menschen länger als sich selbst wahrgenommen. Wie ist überhaupt ein positives Wesen ohne den Gegensatz gegen ein negatives denkbar; nur diesem Gegensatze verdankt es seine Scheinexistenz. ${ }^{50}$

Genau diese vermeintliche Gegensätzlichkeit von Schatten und Mensch wird auch Nietzsche bestreiten und nur Grade des Schattenhaften akzeptieren. Aus dem Spiel mit den Perspektiven läßt Fechner eine Argumentation folgen, in der Nietzsches allzumenschlich fröstelnder Schatten aus dem Schlußdialog von WS $^{{ }^{1}}$ präfiguriert zu werden scheint:

Sagt nun der Mensch: Ei, ich weiß doch recht wohl, daß ich wirklich existire, da bin ich ja; erwidert der Schatten: Nun, da bin ich ja auch. Man sieht mich, man empfindet meine Küble. Wäre ich nicht, wie könnte man von mir sprechen. Dem Menschen will inzwischen nichts einleuchten. Natürlich von einem Schatten kann nichts einleuchten; ich will daher meine Lampe herzubringen. ${ }^{52}$ Wäre der Schatten blos Nichts,

49 Ebd., S. 248 f.

5० Ebd., S. 249.

5 I WS, Schlußdialog: »Der Rasen ist feucht, mich fröstelt. [...] gehe mir ein Wenig aus der Sonne, es wird mir zu kalt.«

$52 \mathrm{Vgl}$. die Laterne des Diogenes in WS I 8. 
so möchte ich sein Leben nicht vertheidigen; nun aber ist er weniger als Nichts, und dies kommt ihm zu statten. Was fühlt man doch stärker, die Sattheit oder den Hunger? Kinder und Völker sind still, wenn sie das Nöthige haben, schreien aber um alles, was ihnen fehlt; - so wirkt also weniger als was sogar mehr als was. Warum soll denn nun die Natur nicht da, wo das Licht fehlt, ebensogut Lichthunger fühlen, als wir da, wo Speise, Preßfreiheit u. dergl. fehlt?

Man erwidert vielleicht: nicht die Natur, sondern der Schatten soll ja fühlen. Wenn auch die Natur an der Schattenstelle etwas fühlte, so wäre doch der Schatten so wenig ein selber lebendes Wesen, als die Kälte, die ich am Beine fühle. ${ }^{33}$

Fechners weitere Argumentation ist strikt naturalistisch und nimmt wiederum spätere Einsichten Nietzsches vorweg. Alles sei organische Natur, der Mensch ebenso wie der Schatten:

Aber was ist denn der ganze Mensch selber Andres als ein Gewebe und Gefolge von Naturgefühlen, nur losgelöst vom übrigen Grunde der Natur. Löst sich denn aber der Schatten nicht so scharf als der Mensch aus der übrigen Natur heraus? Was ist schärfer, als der Absatz des Schattens von dem umgebenden Lichte? Ist also nur Gefühl am Schatten, so fühlt er auch mindestens so selbständig als der Mensch, weil er sich eben so selbständig von der übrigen Natur loslöst. ${ }^{54}$

Der Mensch aber unterliege der Denknotwendigkeit, Fiktion und Wirklichkeit scheiden zu müssen, er bedarf wie bei Nietzsche der Illusion von Sicherheit und werde daher, so Fechner,

immer irgendwelche handgreifliche Unterlage für das Fühlende oder Gefühl verlangen, und das Gefühl des Schattens so lange für einen Schatten des Gefühls zu halten fortfahren, als er den Schatten selber nicht mit Händen greifen kann; denn so

53 Dr. Mises, Kleine Schriften, S. 249 f. Hvg. C.Z.

54 Ebd., S. 250 of. Vgl. das Changieren des Schattens zwischen leibhafter und scheinhafter Existenzform im Kapitel Der Schatten in Za IV. 
sehr er darauf hält, daß der Geist ein immaterielles Wesen sei und bleibe, will er doch seine Immaterialität eben in der Materialität bestätigt haben [...]. Aber die Materie, aus der unser Körper besteht, wechselt ja auch beständig [...]. Ob nun, wie beim Menschen, nach und nach verschiedene Materie durch eine Form durchstreicht, oder wie beim Schatten eine Form nach und nach über verschiedene Materie hinstreicht, kommt im Grunde auf dasselbe heraus. 55

Die Argumentation in Fechners Schattendialog steuert jetzt auf ihren Zielpunkt $\mathrm{zu}$, wiederum mit einem pränietzscheanisch ${ }^{56}$ anmutenden, selbstreflexiven Vergleich des Schattens mit einem Tintenfisch:

Wozu beweisen, sagt man endlich, daß der Schatten fühlen könnte, da er nun doch einmal nicht fühlt. - Und woher weiß man das? - Nun, eben weil man nichts davon weiß, hat man es auch nicht anzunehmen. - Aber ganz eben so wird es ja wieder dem Schatten mit uns gehen. Denken, fühlen, wollen wir deshalb weniger, weil der Schatten von unserem Denken, Fühlen, Wollen nichts weiß? Wie wollen wir nun so ungerecht sein, ein solches Argument gegen den Schatten anzuwenden. $\mathrm{Ob}$ er freilich gerade so vielerlei denkt und fühlt, als wir, kann ich nicht behaupten, aber das Gegentheil läßt sich auch nicht behaupten. Da viel Feines in einem Menschen vorgehen kann, was ein anderer nicht bemerkt, könnte um so mehr auch vieles im Schatten vorgehen, was unsern Augen entgienge. Jedenfalls, wenn im Schatten, wie in uns hienieden, sich das Wechselspiel von Gefühlen und Gedanken an gröbere und feinere Aenderungen des Leiblichen knüpft, so sehen wir

55 Dr. Mises, Kleine Schriften, S. 25 I.

$56 \mathrm{Vgl}$. z.B. »fremd rede ich allen Federfüchsen und Tintenfischen « ( $\mathrm{N}$ I 883, I 8[30]) oder den Brief an Heinrich Köselitz, 2 I. April I886: »Denn es ist ein erschreckliches Buch, das dies Mal mir aus der Seele geflossen ist, - sehr schwarz, beinahe Tintenfisch. «Zum Tintenfisch-Wortspiel vgl. Hans-Gerd von Seggern, Allen Tinten-Fischen feind. Metaphern der Melancholie in Nietzsches Also sprach Zarathustra, in: Nietzscheforschung 9 (2002), S. 263276. 
schon genug davon, um den Schatten nicht für den Aermsten $\mathrm{zu}$ halten. Er wechselt ja beständig nicht nur seine Formen, sondern auch seine Tinten; immer spielen andere Schatten und Seitenlichter in ihn hinein, je nachdem er sich da oder dorthin bewegt. Was fehlt ihm also zur Bedingung eines wechselvollen Gefühls- und Gedankenlebens? Sagt man etwa, dies Spiel hat ja doch keinen Sinn? Aber was hat denn das Farbenspiel, was in unser Auge fällt, für Sinn? Alles, was sich um und an und im Schatten begiebt, fällt ja doch auch in denselben allgemeinen Naturzusammenhang, als das Farbenspiel in unserm Auge; warum soll es für den Schatten weniger Sinn haben, als wenn wir Berge, Bäume, Seen sehen?s7

Fechner resümiert, daß er nur Gründe für das Leben des Schattens finde, aber keine gegen sein Leben.

Ob Fechner einen direkten Einfluß auf Nietzsche ausgeübt hat, ist eine müßige Frage, die wir nicht entscheiden müssen. Wir können auch ohne Antwort darauf die Korrespondenzen zwischen ihren Schattenkonzeptionen für einen aufschlußreichen Vergleich nutzen. Ich erinnere zunächst an eine berühmte Reflexion Nietzsches über die Gradationen des Scheins, die man hat es bislang nicht bemerkt - auch ein Dialog über Schatten ist:

Man gestehe sich doch so viel ein: es bestünde gar kein Leben, wenn nicht auf dem Grunde perspektivischer Schätzungen und Scheinbarkeiten; und wollte man, mit der tugendhaften Begeisterung und Tölpelei mancher Philosophen, die »scheinbare Welt « ganz abschaffen, nun, gesetzt, ibr könntet das, - so bliebe mindestens dabei auch von eurer »Wahrheit « nichts mehr übrig! Ja, was zwingt uns überhaupt zur Annahme, dass es einen wesenhaften Gegensatz von »wahr" und »falsch" giebt? Genügt es nicht, Stufen der Scheinbarkeit anzunehmen und gleichsam bellere und dunklere Schatten und Gesammttöne des Scheins, - verschiedene valeurs, um die Sprache der 
Maler zu reden? Warum dürfte die Welt, die uns etwas angeht -, nicht eine Fiktion sein? Und wer da fragt: »aber zur Fiktion gehört ein Urheber? « - dürfte dem nicht rund geantwortet werden: Warum? Gehört dieses »Gehört « nicht vielleicht mit zur Fiktion? Ist es denn nicht erlaubt, gegen Subjekt, wie gegen Prädikat und Objekt, nachgerade ein Wenig ironisch zu sein? Dürfte sich der Philosoph nicht über die Gläubigkeit an die Grammatik erheben? Alle Achtung vor den Gouvernanten: aber wäre es nicht an der Zeit, dass die Philosophie dem Gouvernanten-Glauben absagte? - (JGB 34, Hvg. zu den Schatten C.Z.)

Häufig wird mit solchen kleinen Dialoginszenierungen die Logik der Argumentation unterlaufen, indem die Gültigkeit der Prämissen des Argumentationssystems infrage gestellt und das Gespräch schnell zum endgültigen Stillstand gebracht wird. ${ }^{8}$ Nach dieser (Anti-)Eristik sind etliche der kleineren Dialoge gebaut: »Gesetzt, dass auch dies nur Interpretation ist - und ihr werdet eifrig genug sein, dies einzuwenden? - nun, um so besser. - « (JGB 22) Die Spielart des kurzen Dialogs bezieht ihr Potential offensichtlich nicht aus einer kompositorisch elaborierten Form, sondern eher aus der in den jeweiligen Sprachhandlungen angelegten Möglichkeit zum Selbstbezug der Sprecher auf die Form. Sind die von ihm ansonsten favorisierten Gesprächsintermezzi literarisch eher anspruchslose Experimente mit dem Dialog als kleiner Form, so handelt es sich bei den WS-Dialogen um echte Kandidaten für literarische Dialoge, da sie Aussage, Motivik und Form kunstvoll verknüpfen. Mit WS unternimmt Nietzsche den in seinem Werk komplexesten Versuch, die formalen Möglichkeiten des Dialogs durchzuspielen, er verschränkt Binnen- und Rahmendialoge und gestaltet einzelne Szenen aus.

58 Vgl. zum folgenden meine beiden Untersuchungen: Zittel, Der Dialog als philosophische Form bei Nietzsche; ders., Gespräche mit Dionysos. Nietzsches Rätselspiele. 


\section{Der Rahmendialog von Der Wanderer und sein Schatten}

In Dramen oder Romane eingefügte Dialoge sind der jeweiligen Form subordiniert.59 Gespräche innerhalb von Gedichten und epischen Formen, wie sie bei Nietzsche häufig vorkommen, man denke nur an Also sprach Zarathustra und die DionysosDithyramben, haben offensichtlich andere Funktionen als Dialoge, die selbständig sind. Kompliziert wird es, wenn eine Gedankensammlung durch Leseranreden insgesamt als dialogisch erscheint oder gar einen Dialograhmen erhält - genau dies ist bei WS der besondere Fall.

Der zweiteilige Dialog zwischen dem Wanderer und seinem Schatten, der die gleichnamige Abteilung von MA II einrahmt, wurde seitens der Forschung bereits eingehend untersucht. So gibt es Motivstudien wie jene von Jean-Claude Wolf, der den Schatten z.B. »als terra incognita des Seelenlebens $\ll^{60}$ deutete. Erkannt wurde zudem sowohl der enge Zusammenhang zum Schlußaphorismus Die Hadesfabrt des vorhergehenden Buches der Vermischen Meinungen und Sprüche (VM 408), in dem Nietzsche das eigene Denken als ein permanentes Totengespräch mit den ihm wichtigsten Philosophen beschreibt, als auch, daß die im IV. Teil von Za und in FW 380 wiederkehrende Schattenmotivik auf Platon zurückweist. ${ }^{61}$ Die besondere Dialogform von WS wird indes seltener thematisiert und wenn, dann meist ausgehend vom Spiel mit der Licht-und-Schattenmetaphorik. Diese zeige eine veränderte Haltung Nietzsches zu Platon an, da er sich dadurch nun auf der Motiv- und Formebene eher in dessen Tradition zu stellen scheint, obzwar der platonische Dialog aus dem Mund der Wandererfigur weiterhin Kritik erfährt. Enrico Müller hat in seiner Studie zu Nietzsches Griechenbild in

$59 \mathrm{Zu}$ den unselbständigen Dialogformen vgl. Gerhard Bauer, Zur Poetik des Dialogs, Darmstadt: Wissenschaftliche Buchgesellschaft 1969.

60 Jean-Claude Wolf, Zarathustras Schatten. Studien zu Nietzsche, Fribourg: Academic Press 2004.

6I Werner Stegmaier, Nietzsches Befreiung der Philosophie. Kontextuelle Interpretation des V. Buchs der "Fröhlichen Wissenschaft «, Berlin: de Gruyter 20I 2, S. I03-I05. Vgl. auch FW 380, »Der Wanderer « redet. 
diesem Zusammenhang dargelegt, daß erst der späte Nietzsche »die paradoxe Struktur des platonischen Werkes « gesehen habe, ohne indes seinen »anti-platonischen Reflex « aufzugeben. ${ }^{62}$ Trotz der expliziten Ablehnung und der Umkehrung zentraler platonischer Motive schließe Nietzsche auf der Stilebene an die Dialogtechnik Platons an. Es sei ja nicht Nietzsche, der den Dialog kritisiert, sondern eine Rollenfigur, und diese erteile dem platonischen Dialog, nicht dem Dialog per se eine Absage. Nietzsche lasse zudem den Wanderer ähnlich wie Platon seinen Sokrates im Phaidros argumentieren, er verwende die platonische Licht-Schattenmetapher wie Sokrates im Sophistes und in der Politeia und tue all dies noch dazu in einer dialogischen Sequenz - glaube dabei jedoch, mit dieser dreifachen Wiederholung Platons (auf Aussage-, Metaphern- und Formebene) - und das ist Enrico Müllers Punkt - einen anti- oder außerplatonischen Formbegriff zu artikulieren.

Werner Stegmaier wiederum liest den WS-Rahmendialog entspannter, erkennt in dem Licht-und-Schattenspiel Orientierungsmöglichkeiten für die Gesprächspartner, die in wechselnden Lichtverhältnissen je anders miteinander kommunizieren können und in ihren Konturen dabei für den andern wie für sich selbst erst wahrnehmbar werden. ${ }^{63}$ Für Nietzsche trage daher der Schatten ebenso zur Erkenntnis bei wie das Licht. Auf der »Oberflächen- und Zeichenwelt« (FW 354) verschwänden die Schattierungen jedoch, Dritten erscheine die Kommunikation opak, sie müßten sich vielmehr ihre eigenen Schatten und mit diesen ihre eigene gemeinsame Sprache suchen, so auch der Leser. ${ }^{64}$

Betrachtet man dagegen den WS-Rahmendialog vor dem Hintergrund der romantischen Tradition, gerät er allerdings in ein den Orientierungssinn verwirrendes Zwielicht. Denn das Wechselspiel von Fragen und Antworten zwischen Wanderer und Schatten ist geprägt von gestaffelt angeordneten Irritationen, die

62 Enrico Müller, Die Griechen im Denken Nietzsches, Berlin: de Gruyter 2005, S. 232.

63 Stegmaier, Nietzsches Befreiung der Philosophie, S. Io4.

64 Ebd. 
an die denkakrobatischen Fiktionsbrüche der Frühromantiker erinnern. Was sich innerhalb dieses Dialogs entspinnt, ist offensichtlich kein sokratisches Gespräch, bei dem z.B. der fragende Wanderer den Schatten in Widersprüche verstrickt und ihn so zu einer höheren Argumentationsstufe führt. Auch hat im Unterschied zum platonischen Dialog keiner der beiden die Gesprächsführung inne. Stattdessen werden zunächst die Gewißheiten des Wanderers erschüttert, was diesen in der Folge jedoch in die Lage versetzt, weit grundsätzlichere Verunsicherungen herbeizuführen, die letztlich die ganze Kommunikationssituation aushebeln.

Zuerst spricht der Schatten den Wanderer an, der deswegen in Verwirrung gerät und sich fragt, ob er nicht sich selber höre. Als ihm klar wird, daß er die Stimme des Schattens hört, glaubt er es zuerst nicht, sondern meint zu halluzinieren, wie einst, als er »in einem Walde bei Pisa erst zwei und dann fünf Kameele sah « (WS, Anfangsdialog). ${ }^{65}$ Der Schatten aber nutzt diese Verunsicherung sogleich als Gelegenheit, um aus der direkten Kommunikation auszusteigen und dem Wanderer die Bedingungen des Gesprächs zu soufflieren. Man solle sich gerade nicht wechselseitig einer sokratischen Prüfung unterziehen, sondern lieber alles im Ungefähren schwebend halten:

Der Schatten: Es ist gut, dass wir Beide auf gleiche Weise nachsichtig gegen uns sind, wenn einmal unsere Vernunft stille steht: so werden wir uns auch im Gespräche nicht ärgerlich werden und nicht gleich dem Andern Daumenschrauben anlegen, falls sein Wort uns einmal unverständlich klingt. Weiss man gerade nicht zu antworten, so genügt es schon, Etwas zu sagen: das ist die billige Bedingung, unter der ich mich mit Jemandem unterrede. Bei einem längeren Gespräche wird auch der Weiseste einmal zum Narren und dreimal zum Tropf. (WS, Anfangsdialog; vgl. Abb. 6 auf S. 34)

65 Dies ist eine ironisch-biographische Reminiszenz, denn Nietzsche hatte am 24. Oktober I 876 tatsächlich Dromedare bei Pisa gesehen, vgl. Paolo D’Iorio, Nietzsche in Sorrent, Stuttgart: Metzler 2020, S. I9-2 I. 
Das nachsichtige Akzeptieren auch von Positionen, die man nicht versteht, der Verzicht auf Gängelei und Festnageln des anderen auf seine Aussagen und das Mißtrauen gegen längere Gespräche werden also zuerst vom Schatten als Modi vorgeschlagen. Diese ungewöhnliche Form des zwanglos-höflichen Miteinandersprechens ist - das wird manche Interpreten gewiß überraschen - gerade charakteristisch für viele von Nietzsches kleinen Dialogen, denen es meist weder um die Vermittlung von Wissen noch um Macht - und schon gar nicht um öffentlichen Disput auf der Bühne geht. Stattdessen werden intime und kryptische Gesprächsformen erprobt, die gerade nicht darauf hinauslaufen, Positionen, Botschaften und Wahrheiten auszutauschen, sondern eher darauf, auf eine ästhetisch ansprechende Weise klug, höflich und milde miteinander umzugehen. In den meisten Dialogen Nietzsches regieren somit gerade nicht das Triumphieren, Vernichten, Rechtbehalten, sondern Vorsicht und Rücksicht, der Verzicht auf Widerlegung, das Geltenlassen anderer Positionen, das Nicht-verstanden-werden-Wollen und das Nicht-verstehen-Müssen.

So auch hier: Wenig später stimmt der Wanderer dem Vorschlag des Schattens zu. Es fällt die anti-agonale Haltung der Sprechenden auf und daß betont wird, daß es weniger auf den Gegenstand des Gesprächs ankommt als darauf, daß Licht und Schatten im Zusammenspiel sowohl der Rede als auch dem Charakter Kontur verleihen:

Der Wanderer: Ich merke erst, wie unartig ich gegen dich bin, mein geliebter Schatten: ich habe noch mit keinem Worte gesagt, wie sehr ich mich freue, dich zu hören und nicht blos zu sehen. Du wirst es wissen, ich liebe den Schatten, wie ich das Licht liebe. Damit es Schönheit des Gesichts, Deutlichkeit der Rede, Güte und Festigkeit des Charakters gebe, ist der Schatten so nöthig wie das Licht. Es sind nicht Gegner: sie halten sich vielmehr liebevoll an den Händen, und wenn das Licht verschwindet, schlüpft ihm der Schatten nach. (WS, Anfangsdialog; vgl. Abb. 6) 
Hier also ist der Schatten gleichberechtigt an den Akten der Wahrnehmung und der Erkenntnis beteiligt - die klare und distinkte Erkenntnis ist gerade nicht exklusives Resultat des Lichtes der Vernunft; im hellen Licht erkennt man nur etwas, wenn die Schatten den Gegenständen wie den Worten ihre Physiognomie verleihen. Das ist ein Gedanke, der schon in Lavaters Physiognomik eine Rolle spielte ${ }^{66}$ und seinerzeit die Mode begründete, Schattenrisse von Personen anzufertigen und über diese deren Wesen zu erschauen.

Der Schatten kritisiert entsprechend nicht die »Lichtjünger«, also die Aufklärer, sondern erklärt, diese »unermüdlichen Erkenner und Entdecker « zu lieben. Er erweitert so die traditionelle Lichtmetaphorik der Aufklärung, indem er in einer postcartesianischen Meditation aus den Täuschungen folgert:

Jener Schatten, welchen alle Dinge zeigen, wenn der Sonnenschein der Erkenntniss auf sie fällt, - jener Schatten bin ich auch. (WS, Anfangsdialog; vgl. Abb. 7 auf S. 35)

Cogito ergo dubito. Was sich hier vollzieht, ist keine Umkehrung des Platonismus, sondern des Cartesianismus. Das Ich findet anstatt in der Selbstvergewisserung der Vernunft in der Identifikation mit dem äußeren sinnlichen Trugbild seinen Grund. In einer ersten Fassung von WS gab es just an dieser Stelle einen Einschub, in welchem der Schatten noch einen leisen Zweifel geäußert hatte:

66 Vgl. »Aus bloßen Schattenrissen hab' ich mehr physiognomische Kenntnisse gesammelt, als aus allen übrigen Porträten; durch sie mein physiognomisches Gefühl mehr geschärft, als selber durch's Anschauen der immer sich wandelnden Natur. - Der Schattenriß faßt die zerstreute Aufmerksamkeit zusammen; concentriert sie bloß auf Umriß und Gränze, und macht daher die Beobachtung einfacher, leichter, bestimmter; - die Beobachtung und hiemit auch die Vergleichung. Die Physiognomik hat keinen zuverlässigern, unwiderlegbarern Beweis ihrer objektifen Wahrhaftigkeit, als die Schattenrisse." (Johann Caspar Lavater, Physiognomische Fragmente, zur Beförderung der Menschenkenntniß und Menschenliebe, Bd.2, Leipzig, Winterthur: Weidmanns Erben und Reich, Heinrich Steiner und Compagnie I 776, S. 9). 
Der Schatten. Wahr oder unwahr, deine Worte thun mir wohl: waren sie auch aufrichtig gesprochen? fast klang mir's, als ob deine Eitelkeit dir sie eingeflüstert hatte. (WS, Anfangsdialog, Entwurf)

Da aber beruhigt er sich mit folgendem Urteil, mit dem zugleich auf Andersens Schatten angespielt zu werden scheint, dessen Stolz es ja war, mit einem redenden Schatten aufwarten zu können:

Der Schatten. [...] Ein redender Schatten ist aber eine Seltenheit, auf welche es erlaubt ist eitel zu sein; deshalb halte ich deine Freude für aufrichtig.

Der Wanderer. Du kannst also nicht im Herzen lesen, aber liebst es, Vermuthungen zu machen, was darauf geschrieben steht? Das liebe ich auch.

Der Schatten. Jetzt bist du es, der eine Gleichheit zwischen uns wahrnimmt. (WS, Anfangsdialog, Entwurf) ${ }^{67}$

Schatten und Wanderer machen einander in der Folge viele Komplimente, der Wanderer räumt ein:

Ich glaube dich zu verstehen, ob du dich gleich etwas schattenhaft ausgedrückt hast. Aber du hattest recht: gute Freunde geben einander hier und da ein dunkles Wort als Zeichen des Einverständnisses, welches für jeden dritten ein Räthsel sein soll. Und wir sind gute Freunde. Desshalb genug des Vorredens! [...] Sehen wir zu, worüber wir in aller Eile und Friedfertigkeit mit einander zusammenkommen. (WS, Anfangsdialog; vgl. Abb. 7)

Schattenhafte Ausdrücke, dunkle Worte ${ }^{68}$ als Zeichen, offenbar wird hier auch ein linguistisches Spiel mit Zeichen gespielt -

67 Zitiert nach KSA I4, S. I 83; KGW IV 4, S. 302.

$68 \mathrm{Vgl}$. I. Korinther I3.II-I2: »Da ich ein Kind war, da redete ich wie ein Kind und war klug wie ein Kind und hatte kindische Anschläge; da ich aber ein Mann ward, tat ich ab, was kindisch war. Wir sehen jetzt durch einen Spiegel in einem dunkeln Wort; dann aber von Angesicht zu Angesicht. 
ähnlich wie bei Fechner, dessen Schatten viele Tinten kennt; und wenn wir dieses ein wenig weiterspielen, bemerken wir: Normalerweise ist die »Zeichenhaftigkeit des Schattens « insofern exemplarisch, als der Schatten »mit dem Objekt, das er verdoppelt, strikt zeitgleich, [...] simultan und unablösbar ist «.69 Löst sich nun aber der Schatten doch, so können auch die Zeichen ihre Referenzfunktion hinsichtlich der wirklichen Welt aufgeben und in ein freies Spiel von selbstreferentiellen Zeichen eintreten, das nun die Welt des Scheins als wirklich setzt. Aber auch im Schattenreich der Fiktion, so der Wanderer, sei die adäquateste Form das Zwiegespräch. Man spreche zwar auch hier miteinander schattenhaft und dunkel, doch wisse man mit Andeutungen umzugehen. Dritten erscheine ein solches Einverständnis kryptisch - sie bleiben ausgeschlossen.

Nun ist es an dem Wanderer, aus dieser Einsicht metareflexive Konsequenzen zu ziehen, die allerdings nicht nur den aktualen Dialog selbst betreffen, sondern auf das ganze Buch WS ausgreifen. »[G]enug des Vorredens « (WS, Anfangsdialog), entfährt es ihm, auf die Funktion des von ihm selbst geführten Dialogs, Vor- und Nachrede eines Buches zu sein, hinweisend. Passend wird nun die klassische Diskussion platonischer Schriftkritik aufgenommen:

Der Schatten: Aber die Schatten sind schüchterner, als die Menschen: du wirst Niemandem mittheilen, wie wir zusammen gesprochen haben!

Der Wanderer: Wie wir zusammen gesprochen haben? Der Himmel behüte mich vor langgesponnenen schriftlichen Gesprächen! Wenn Plato weniger Lust am Spinnen gehabt hätte, würden seine Leser mehr Lust an Plato haben. Ein Gespräch, das in der Wirklichkeit ergötzt, ist, in Schrift verwandelt und gelesen, ein Gemälde mit lauter falschen Perspectiven: Alles ist zu lang oder zu kurz. - Doch werde ich vielleicht

Jetzt erkenne ich's stückweise; dann aber werde ich erkennen, gleichwie ich erkannt bin.«

69 Viktor I. Stoichita, Eine kurze Geschichte des Schattens, München: Fink I999, S. I 68. 
mittheilen dürfen, worüber wir übereingekommen sind? (WS, Anfangsdialog; vgl. Abb. 7)

Erinnern wir uns, daß nach Plinius die Malerei ihren Ursprung im Schatten eines Menschen hat, dessen Linien jemand auf einer Wand nachzog. ${ }^{70}$ Der Vergleich des schriftlichen Dialogs mit einem Gemälde ist also nicht zufällig gewählt. Worte niederschreiben ist wie Gedanken malen.

Seltsamerweise soll aber nur das Wie des Sprechens durch Verschweigen geschützt werden, das Was der Rede könne auch in anderer Darstellungsform schriftlich mitgeteilt werden. Form und Inhalt wären also partiell trennbar, und die Aphorismen, Sentenzen, Kurzessays und Gedanken in WS wie auch andernorts erschienen so als äußerliche Darstellungsformen, mit denen lediglich Resultate von Gesprächen mitgeteilt werden, »nicht aber deren Verlauf in Licht und Schatten. $\ll^{7 \mathrm{I}}$

Die Reduktion der literarischen Darstellungsfunktion durch den Wanderer auf eine nachträgliche Wiedergabe nicht mitteilbarer Gespräche irritiert, denn bekanntlich ist für Nietzsche ein »Aphorismus, rechtschaffen geprägt und ausgegossen, [...] damit, dass er abgelesen ist, noch nicht >entziffert<; vielmehr hat nun erst dessen Auslegung zu beginnen, zu der es einer Kunst der Auslegung bedarf.«(GM, Vorrede, 8) Diese Auslegung könnte herauszufinden versuchen, wie das bei der nachträglichen Niederschrift verschwiegene mündliche Gespräch verlaufen sein könnte. Es gibt jedoch in WS nicht nur Aphorismen, innerhalb derer zuweilen kleine Gespräche inszeniert werden, sondern auch weitere Dialoge, die auf der gleichen Ebene wie die Aphorismen liegen. Der Aphorismus ist keinesfalls der Oberbegriff für alle literarischen Formen in Nietzsches Schriften und auch nicht in WS. Diese Binnendialoge verbergen aber offensichtlich nicht ein Gespräch, sondern stellen es dar. Wie verhalten sie sich zur Kritik des Wanderers am Dialog?

70 Ebd.

7I Stegmaier, Nietzsches Befreiung der Philosophie, S. Io4. 
Paul Friedländer meinte, es sei der $\gg$ Dialog [...] die einzige Form des Buches, die das Buch selber aufzuheben scheint «, ${ }^{22}$ da er seine Literarizität vergessen machen könne. In der älteren Platonforschung war insbesondere Schleiermacher der Ansicht, daß aus diesem Grund der platonische Dialog von der Schriftkritik Platons ausgenommen sei - nur er gebe die Lebendigkeit eines Gesprächs adäquat wieder, seine Schriftform trete unbemerkt zurück. ${ }^{73}$ Genau dieser Auffassung widerspricht der Wanderer. Für ihn tritt insbesondere der geschriebene Dialog in Opposition zum Gespräch, das er notwendig entstellt und verzerrt, und dies gilt in seinen Augen nicht nur für die platonischen Dialoge, sondern für jeden Lese-Dialog.

Auch in Schleiermachers Übersetzung spricht Phaidros von der »lebenden und beseelten Rede des wahrhaft Wissenden, von der man die geschriebene mit Recht wie ein Schattenbild ansehn« könne (276a). Ob man dies aber - wie jüngst Tobias Brücker vorschlug - so deuten kann, daß der Wanderer daher in einen Dialog mit der Schrift trete, für die der Schatten stehe, ${ }^{74}$ bezweifle ich. Erstens wird in Platons Text die Schrift (graphae) nicht als Schattenbild (skia) der Rede bezeichnet - sondern als deren Abbild (eidolon), ${ }^{75}$ und zweitens stimmt, selbst wenn man Schleiermacher folgt, die damit verbundene Abwertung der Schrift nicht mit der Gleichberechtigung des Schattens innerhalb des WS-Dialogs überein. »Vielfach muß anders geschrieben als gesprochen werden. Deutlichkeit ist Vereinigung von Licht und Schatten« heißt es in einem (auch von Brücker angeführten)

72 Paul Friedländer, Platon, Bd. I, Berlin: de Gruyter 1928, S. I77.

73 Vgl. dazu Thomas Alexander Szlezák, Abbild der lebendigen Rede. Was ist und was will ein platonischer Dialog? in: Museum Helveticum 66,2 (2009), S. 65-83; ders., Gilt Platons Schriftkritik auch für die eigenen Dialoge? Zu einer neuen Deutung von Phaidros 278 b8-e4, in: Zeitschrift für philosophische Forschung 53,2 (1999), S. 259-267.

74 Brücker, Auf dem Weg zur Philosophie, S. 75.

75 Siehe zum Ausdruck »Schattenbild « die luziden Ausführungen bei Wolfram Groddeck, "Ebenbild « und»Narben". Poetische Revision beim späten Hölderlin und der Ort der Handschrift, in: »Mir ekelt vor diesem tintenklecksenden Säkulum«. Schreibszenen im Zeitalter der Manuskripte, hg. von Davide Giuriato, Martin Stingelin, Sandro Zanetti, München: Fink 2004, S. I75-190; hier S. I 8 I-I 83 . 
Nachlaßnotat aus dem Jahr i 876 (N i 876, is [27]). Drittens wird auch der Wanderer in Schrift verwandelt. Für das ganze Buch WS ergeben sich hieraus dennoch interessante Konsequenzen im Hinblick darauf, wie in ihm die Beziehungen zwischen Gespräch und Dialog sowie zwischen Dialog und Aphorismus gestaltet werden.

Rekapitulieren wir: Die Wanderer-Schatten-Dialoge stehen am Anfang und Ende der Schrift und rahmen sie; alles, was dazwischen liegt, wird vom Wanderer als Resultat dieser Gespräche bezeichnet. Auch die sog. Aphorismen seien daher die Früchte der Gespräche, die nur anders dargestellt werden, da sie, würden sie als geschriebener Dialog wiedergegeben, ein Gemälde mit lauter falschen Perspektiven abgäben, wo alles zu lang oder zu kurz sei.

Wenn jedoch der Dialog als schriftlich fixiertes Gespräch dieses verzerrt und zugleich angekündigt wird, innerhalb des Buches sei deshalb eine andere Darstellungsweise zu wählen, sich im Buch dann aber doch Dialoge finden - welches ist dann deren Status, und welches ist der Status des Dialogs, in dem die Verzerrung durch die Schrift als notwendig behauptet wird?

Entweder sind diese Dialoge also notwendig verzerrt, oder es wurde eine neue Form des Dialogschreibens gefunden, die die Verzerrungen vermeidet oder ausgleicht. Das Besser-SchreibenLernen wird gerade in WS nachdrücklich gefordert (WS 87). Jedenfalls spricht Nietzsche ausdrücklich von einem "Anfangsund Schluß-Dialog [!], in denen gute Stimmung ist (und eine Masse psychologischer Kleinigkeiten; das Schattenmachen am Schluß des Ganzen zB. (Kränkung Bedauern Abschied NaturStimmung des Abends durcheinander gemischt) $\ll,{ }^{6}$ und nicht von einem Gespräch. Aber auch die kleinen, innerhalb von Aphorismen eingestreuten Gesprächsintermezzi inszenieren schriftlich eine mündliche Lebendigkeit. Die in WS eine eigene Einheit bildenden Dialoge sind länger als diese, aber auch nicht so lang wie ein platonischer Dialog; ihr Umfang scheint also der Wanderer-Kritik Rechnung zu tragen. 
Da der Wanderer aber seine Kritik am Dialog innerhalb eines schriftlich fixierten Dialogs formuliert, wird diese Kritik entweder qua Form unterlaufen oder als schiefe Aussage deklariert. Vor allem wird durch das Insistieren des Wanderers auf die fatale Wirkung des schriftlichen Fixierens erst deutlich, daß er selbst wie der Schatten eine erschriebene Figur ist, aber nur der Schatten sich und uns über seinen fiktiven Status nicht hinwegtäuscht. Ist die im Rahmendialog geäußerte Dialogkritik daher bereits performatives Exempel eines unverzerrten Miteinandersprechens, oder wird die Verzerrung dialogisch vorgeführt und die Kritik so relativiert? Man kann es nicht herausbekommen, die Grenze von Gespräch und Dialog wird durch die vertrackte Darstellungsform immer wieder verschoben. Werfen wir daher noch einen letzten Blick auf das Ende des Schlußdialogs, der zugleich das Ende des ganzen Buches WS markiert:

Der Wanderer: Und könnte ich dir nicht in aller Geschwindigkeit noch Etwas zu Liebe thun? Hast du keinen Wunsch?

Der Schatten: Keinen, ausser etwa den Wunsch, welchen der philosophische »Hund « vor dem grossen Alexander hatte: gehe mir ein Wenig aus der Sonne, es wird mir zu kalt.

Der Wanderer: Was soll ich thun?

Der Schatten: Tritt unter diese Fichten und schaue dich nach den Bergen um; die Sonne sinkt.

Der Wanderer: - Wo bist du? Wo bist du?

Ein rätselhafter Schluß. Es scheint, als ob der Schatten verschwände und der Wanderer nun, von diesem befreit, alleine bleibe: Die Sonne sinkt - diesen Titel wird Nietzsche einem seiner Dionysos-Dithyramben geben, in welchen das Licht der Abenddämmerung mit dem Tod verbunden wird: »Heiterkeit, güldene, komm! / du des Todes / heimlichster süssester Vorgenuss!«(DD, Die Sonne sinkt).

Aber wie ist die Aufforderung, aus der Sonne zu gehen, zu begreifen? Der Wanderer kann ja nicht einfach wie Alexander zur Seite treten, um dem Schatten aus der Sonne zu gehen, das ist schlicht unmöglich - er kann nur in den Schatten gehen! Er tritt 
bei untergehender, tiefstehender Sonne unter die Fichten ${ }^{77}$, um ihn wird es dunkel, von hinten überwölbt der große Schatten des Waldes den Wanderer, und in diesem Schatten geht sein Schatten auf. Am Ende ist alles dunkel, das Ende ist dunkel. Der Wanderer hat zwar das letzte Wort, auf der Ebene der Anschauung aber dominiert der Schatten das Schlußbild. Ein Ende in kalter Finsternis!

\section{Schattenspiele in Also sprach Zarathustra}

Im Zarathustra ${ }^{78}$ nun werden die Schattenmotive aus WS zusammengeführt und das Verwirrspiel noch weiter getrieben.79 Im zweiten Teil sehen die auf den glückseligen Inseln von Bord

77 Zum Fichtenwald siehe auch WS 295.

78 Also sprach Zarathustra ist im Hinblick auf Nietzsches Dialoge ein besonderer Fall, wiewohl auch hier das Verhältnis von Sprechen und aufgeschriebenem Gespräch zentral ist. Die verbreitete Ansicht, es gebe in Za kaum Dialoge, sondern vielmehr Monologe oder Reden an andere, ist falsch; es wird in Za sehr viel miteinander gesprochen. Dennoch sind diese Gespräche stets in eine Handlung eingebunden, welche sie strukturiert. Es wird aber immerhin ein Kapitel explizit als das Gespräch mit den Königen (Za IV) bezeichnet und "Zarathustra's Gespräch mit dem Feuerhunde $(\mathrm{Za}$ II, Von grossen Ereignissen) nacherzählt. Zudem kommt es immer wieder zu kleineren Gesprächsintermezzi, die keine strukturbestimmende Dominanz erreichen. Es fällt aber auf, daß es dann im dritten und vierten Buch zu einer langen Serie von Begegnungen zwischen Zarathustra und verschiedenen Gesprächspartnern kommt, denen jeweils ein eigenes Kapitel gewidmet ist, das durch den Dialog beherrscht und mehr oder weniger strukturiert wird: so z.B. mit dem schäumenden Narren (Vom Vorübergehen), den Tieren (Der Genesende), mit dem Wahrsager (Der Nothschrei), den Königen, dem Gewissenhaften des Geistes (Der Blutegel), dem Zauberer (Der Zauberer), dem alten Papst (Ausser Dienst), dem hässlichsten Menschen, dem freiwilligen Bettler, und eben auch mit dem Schatten.

79 Zum Schattenmotiv im Za vgl. Katharina Grätz, Der Dichter verräth sich in seinen Gestalten, die die wechselnden Rollenidentitäten Zarathustras und mit diesem Wechsel einhergehenden Perspektivierungen beschreibt. Vgl. zur Rollenprosa des Za auch: Claus Zittel, Das ästhetische Kalkül von Friedrich Nietzsches "Also sprach Zarathustra" (Nietzsche in der Diskussion), Würzburg: Königshausen und Neumann 2000 (2. Auflage 20II); ders., Sprüche, Brüche, Widersprüche. Irritationen und Deutungsprobleme beobachtet am Erzäblverhalten und an der Erzäblperspektive in Nietzsches "Also sprach Zarathustra", in: Nietzscheforschung 9 (2002), S. 289-300. 
gegangenen Schiffsleute »plötzlich durch die Luft einen Mann auf sie zukommen, und eine Stimme sagte deutlich: ses ist Zeit! Es ist die höchste Zeit!« Diese Gestalt fliegt dann »aber schnell gleich einem Schatten vorbei«, und zu ihrer Bestürzung erkennen sie in ihr Zarathustra (Za II, Von grossen Ereignissen). Als sie später Zarathustra davon erzählen, fragt sich dieser: »Was soll ich davon denken! [...] Bin ich denn ein Gespenst? Aber es wird mein Schatten gewesen sein. Ihr hörtet wohl schon Einiges vom Wanderer und seinem Schatten?« (ebd.) Im Kapitel Der Wanderer (Za III) erscheint Zarathustra eben als jener Wanderer, der im Kapitel Von der Seligkeit wider Willen (Za III) wiederum bekennt: »Und wahrlich, Zeit war's, dass ich gieng; und des Wanderers Schatten und die längste Weile und die stillste Stunde - alle redeten mir zu: >es ist höchste Zeit!« Als aber im 4. Teil Zarathustra im Gebirge unterwegs ist, ruft plötzlich hinterrücks sein Schatten: »Halt! Zarathustra! So warte doch! Ich bin's ja, oh Zarathustra, ich, dein Schatten!«« Es kommt zu einer absurden Verfolgungsjagd und endlich zum Dialog mit dem Schatten, ${ }^{80}$ und in diesem erklärt der Schatten, daß er der Wanderer sei, der heimatlos wie Ahasver für alle Zeit durch die Welt ziehe: »Ein Wanderer bin ich, der viel schon hinter deinen Fersen her gieng. Immer unterwegs, aber ohne Ziel, auch ohne Heim « (Za IV, Der Schatten). Dieser erznihilistische Schatten ist es, von dem die oft Nietzsche in den Mund gelegten berühmten Aussprüche stammen: »Nichts ist wahr, alles ist erlaubt [...]. Oh ewiges Überall, oh ewiges Nirgendswo, oh ewiges - Umsonst! « (Za IV, Der Schatten).

Wieder ist es also der Schatten, der den Dialog eröffnet, doch anders als dem Wanderer macht seine unheimliche Erscheinung Zarathustra Angst. Als Zarathustra »ihn nämlich mit Augen prüfte, erschrak er wie vor einem plötzlichen Gespenste: so

80 Es könnte sich hier auch ein Rückbezug auf WS 85, Der Verfolger Gottes ergeben im Sinne einer Kontrafaktur, denn Paulus wäre als Verfolger Gottes gerade ein Kämpfer gegen die Vieldeutigkeit. Vgl. dazu Daniel Havemann, Der "Verfolger Gottes". Paulus in "Der Wanderer und sein Schatten", in: Der "Apostel der Rache«. Nietzsches Paulusdeutung, Berlin: de Gruyter 2002, S. 89-9I. 
dünn, schwärzlich, hohl und überlebt sah dieser Nachfolger aus.« (Za IV, Der Schatten). Dieser Schatten erklärt sich zu Zarathustras Nachfolger, der überall dabei gewesen sei, und erinnert an die gemeinsamen Erfahrungen in der Heimatlosigkeit. Zarathustra erkennt ihn schließlich als seinen legitimen Schatten an:

Also sprach der Schatten, und Zarathustra's Gesicht verlängerte sich bei seinen Worten. »Du bist mein Schatten! sagte er endlich, mit Traurigkeit. Deine Gefahr ist keine kleine, du freier Geist und Wanderer! Du hast einen schlimmen Tag gehabt: sieh zu, dass dir nicht noch ein schlimmerer Abend kommt! (ebd.)

Der Erzähler überläßt dem Schatten Zarathustras Redeformel »Also sprach ...«, und vice versa verlängert er Zarathustras Gesicht in Schattenmanier und erklärt überdies den Schatten zum Wanderer! Doch damit nicht genug. Als Zarathustra zu Beginn des IV. Teils im Kapitel Der Nothschrei vor seiner Höhle saß,

mit einem Stecken in der Hand, und den Schatten seiner Gestalt auf der Erde abzeichnete, nachdenkend und, wahrlich! nicht über sich und seinen Schatten - da erschrak er mit Einem Male und fuhr zusammen: denn er sahe neben seinem Schatten noch einen andern Schatten. Und wie er schnell um sich blickte und aufstand, siehe, da stand der Wahrsager neben ihm[.]

Abermals wird auf das seit Plinius topische Nachzeichnen des Schattens als Ursprung der Malerei angespielt. Der Schattenriß dient als Vehikel physiognomischer Erkenntnis, hier der Selbsterkenntnis, doch gelangt diese zu keinem Ende. Denn wenn hinter Zarathustra der Wahrsager als plötzliche Epiphanie auftaucht, so vereint sein Schatten sich mit dem Zarathustras und verdoppelt ihn zugleich. Durch das Nachzeichnen hat sich der Schatten zu einer weiteren Figur verselbständigt. Die ebenso auffällige wie ungewöhnliche Verdoppelung des Schattens 
korrespondiert mit dem gleichen Motiv bei Chamisso und Andersen, aber auch Fechner konstatierte: Der Schatten »läuft sogar durch andere seines Gleichen durch. Die Schatten, die sich treffen, machen sich nur etwas schwarz, statt daß, wenn sich zwei Menschen begegnen, die sich etwas weiß zu machen pflegen. $\ll^{81}$

Gegen Ende des IV. Teils - im Kapitel Unter Töchtern der Wüste - singt schließlich »der Wanderer, welcher sich den Schatten Zarathustra's nannte", das Nachtisch-Lied: "Die Wüste wächst: weh Dem, der Wüsten birgt! « - doch aus der Selbstbezeichnung des Wanderers als Schatten erwächst eine Doppelexistenz, aus Schein wird Sein, da der Wanderer und sein Schatten nun eins werden (>Da wurde zwei zu eins`). Der Erzähler kommentiert jedenfalls: »Also sprach der Wanderer und Schatten «. Zarathustra, der einst selbst als »ein Schatten dessen, was kommen muss « $(\mathrm{Za}$ II, Die stillste Stunde) angesprochen wurde, wohnt der Szene als Zuschauer bei. Der Schatten, der früher der seine war, hat sich dem Wanderer angeschlossen und hat diesen - im Schattenspiel von Zarathustras Höhle - gedoppelt. Der Wanderer wird im weiteren Fortgang der Handlung konsequenterweise nurmehr mit der Zwillingsformel »Wanderer und Schatten « tituliert, das Possessivpronomen für den Schatten entfällt.

In einer Vorstufe war die enge Verknüpfung mit der seinerzeit in Europa weitverbreiteten Doppelgänger-Thematik noch deutlicher:

Der gute Europäer. / - - - Als er ihn nämlich aber ansah, schrak Zarathustra sein Herz zusammen: so zum Verwechseln ibm selber ähnlich sah sein Nachfolger aus, in der Tracht und dem Bart nicht allein, sondern in der ganzen Art. / Wer bist du? fragte Zarathustra heftig. Oder bin ich's selber? Was treibst du da mit mir, du Possenreißer? Oder wie nenne ich dich? / Vergieb mir, oh Zarathustra, diese Mummerei, antwortete der Doppelgänger und Schatten, und willst du einen Namen für mich, so nenne mich den guten Europäer. / Daß

8 I Dr. Mises, Kleine Schriften, S. $244 \mathrm{f}$. 
ich aber deine Tracht und Art nachmache, das ist gerade jetzt in Europa die gute Mode. Mitunter nannte ich mich auch den Wanderer, I öfter aber noch Zarathustra's Schatten. Und wahrlich ich folgte dir mehr auf den Fersen nach und in ferneren Fernen, als du weißt und argwöhnst. / Willst du mich endlich den ewigen Juden heißen, so zürne ich nicht: ihm gleich bin ich immer unterwegs, ohne Ziel und ohne Heim nur daß ich weder Jude noch auch ewig bin. (Z II ıо, zit. nach KSA I4, S. 337, Hvg. C.Z.)

In dem ihm gewidmeten Zarathustra-Kapitel hat der Schatten als Wanderer endlich die Position seines früheren Herrn eingenommen. Allerdings ist er nicht wie bei Andersen fett geworden, sondern vielmehr abgemagert, gerade so wie in Schlemihls Schutzbehauptung, sein verlorener Schatten sei ihm bei einer Krankheit eingegangen: »Alles nimmt von mir, Nichts giebt, ich werde dünn, - fast gleiche ich einem Schatten « sagt merkwürdigerweise der sich als Wanderer ausgebende Schatten. »Mit dir bin ich in fernsten, kältesten Welten umgegangen, einem Gespenste gleich, das freiwillig über Winterdächer und Schnee läuft« (Za IV, Der Schatten), fährt er fort.

Diese fliegende Gestalt könnte ihr Vorbild in Chamissos Schlemibl haben, in dessen zweitem Teil der Held mit Siebenmeilenstiefeln durch die Welt wandert. Nietzsche kannte sehr wahrscheinlich die berühmten Illustrationen von Cruikshank. Seine Passagen über den fliegenden Schattenmann, der SchattenVerfolgungsjagd im Zarathustra, und den in öden Eisbärzonen wandernden Gespenster-Zarathustra lesen sich jedenfalls wie deren Ekphrasis. ${ }^{82}$

82 Über die Gespenster-Metaphorik ergeben sich im Übrigen weitere Motivverknüpfungen, etwa zu Goethes Augengespenst als Bezeichnung für einen spektral verschobenen Schatten, mit dem sich ein epistemischer Umbruch im Verhältnis von Wahrnehmung und Wirklichkeit artikuliert (vgl. J. Hennig, $\mathrm{Zu}$ Goethes Gebrauch des Wortes "Gespenst ", Deutsche Vierteljahrsschrift für Literaturwissenschaft und Geistesgeschichte 28 (I954), S. 487 ff.), oder zur späteren Vorrede zu MA, in der Nietzsche seine Freien Geister zu Gespenstern in einem Schattenspiel deklariert, mit dem sich schwermütige Einsiedler über ihre Einsamkeit hinwegtrösten »- als ein Schadenersatz 

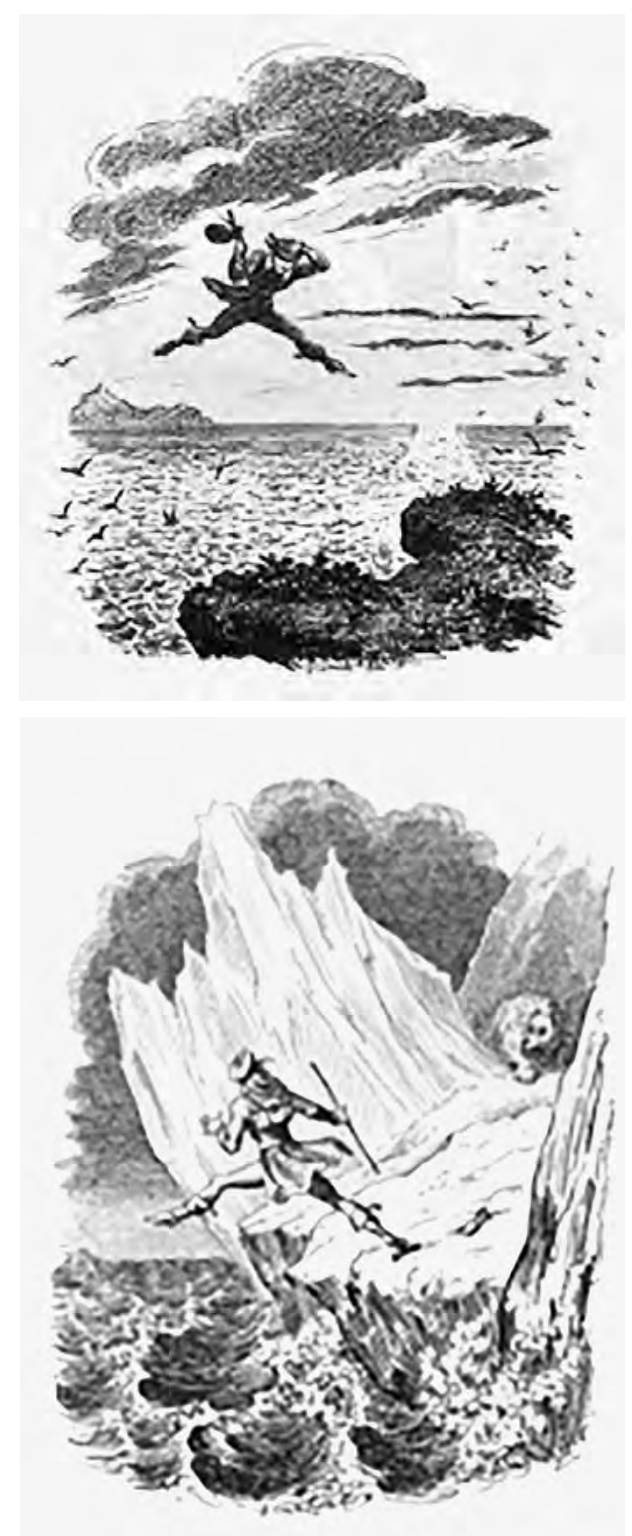

Abb. 25 und 26: George Cruikshank, Illustrationen zur ersten englischen Ausgabe des Peter Schlemihl 1824 
Versuchen wir ein kurzes Fazit: Deutungsschwierigkeiten ergeben sich in Also sprach Zarathustra durch die wechselnden Rollenidentitäten, denn die verschiedenen Figuren nehmen immer wieder auch Positionen von Zarathustra ein und parodieren sie. Die alternierende Verteilung von Positionen und Sprechakten auf verschiedene Figuren torpediert die kommunikative Funktion der Gespräche; ${ }^{3} 3$ auch die performative Erschütterung der Glaubwürdigkeit der Sprecherinstanz wird auf vielfältige Weise inszeniert. Im Zarathustra hat der Dialog mit dem Schatten dabei eine Ausnahmestellung inne. Nimmt man ihn sub specie der literarischen Schattentradition in Augenschein, kann er als eine Art Meta-Dialog interpretiert werden, da er die im Buch häufig vorgenommenen Rollenwechsel selbst zum Thema macht. Anders und paradoxer formuliert: Der Schatten ist das Urbild von Zarathustras Doppelgängern. Die SchattenDialoge zeigen das Reduplizierungsprinzip, welches die Figuren für Nietzsches polyphonen Chor der Stimmen erzeugt, in dem keine Position Vorrecht oder dauerhaften Bestand hat. Es gibt kein wahres Ich hinter den Falschen. Es leben die Schatten. Wir leben als Schatten.

für mangelnde Freunde.« Nietzsche will nicht daran zweifeln, daß es in der Zukunft »dergleichen freie Geister einmal geben könnte [...], leibhaft und handgreiflich und nicht nur, wie in meinem Falle, als Schemen und Einsiedler-Schattenspiel « (MA I, Vorrede, 2). Die »Augengespenster « und den sich in ihnen artikulierenden epistemischen Umbruch im Verhältnis von Wahrnehmung und Wirklichkeit untersucht die Studie von Elisabeth Strowick, Gespenster des Realismus. Wabrnehmung als grundlegendes Darstellungs- und Experimentierfeld der Literatur des Realismus. Zur literarischen Wabrnebmung von Wirklichkeit, Paderborn: Fink 2019.

83 Vgl. dagegen Anke Bennholdt-Thomsen, Nietzsches "Also sprach Zarathustra" als literarisches Phänomen: eine Revision, Frankfurt a.M.: Athenäum I 974, S. I 33 . 
